\title{
Life situation among persons living with inflammatory bowel disease.
}

\author{
Katarina Pihl Lesnovska
}

Department of Medical and Health Sciences Linköping University, Sweden

Linköping 2017

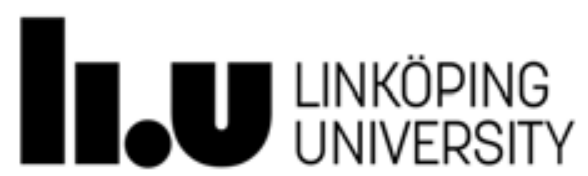


Life situation among persons living with inflammatory bowel disease.

CKatarina Pihl Lesnovska, 2017

Cover/picture/Illustration/Design:

Published article has been reprinted with the permission of the copyright holder.

Printed in Sweden by LiU-Tryck, Linköping, Sweden, 2017

ISBN 978-91-7685-435-8

ISSN 0345-0082 
To those who suffer from inflammatory bowel disease

"It is more important to know what sort of person has a disease than to know what sort of disease a person has."

Hippocrates 


\section{CONTENTS}

ABSTRACT ......................................................................................................... 1

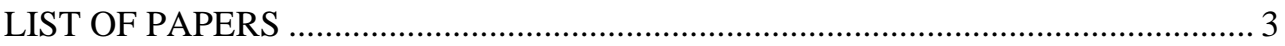

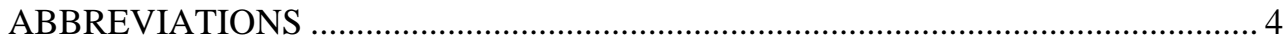

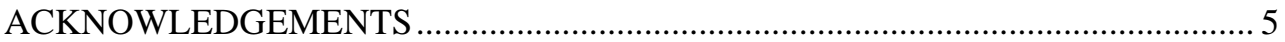

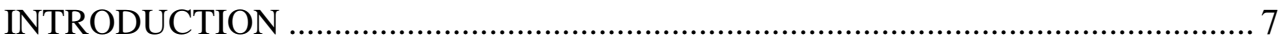

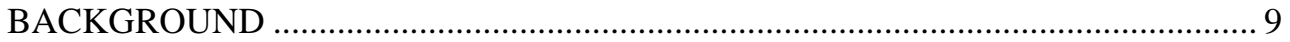

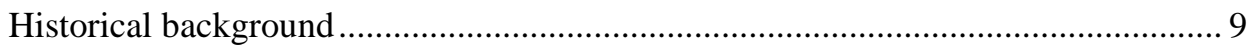

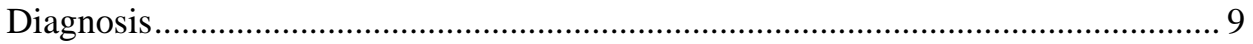

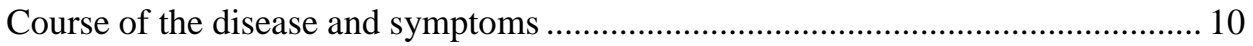

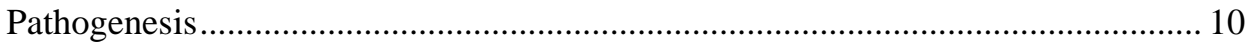

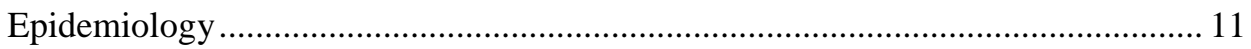

Associated health problems ………................................................................... 11

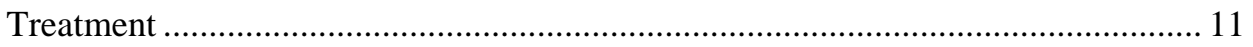

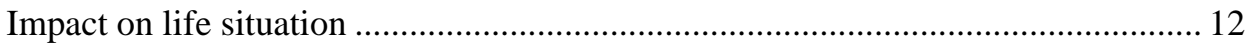

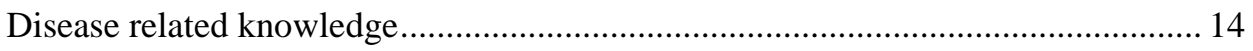

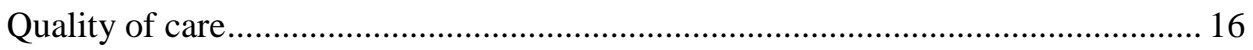

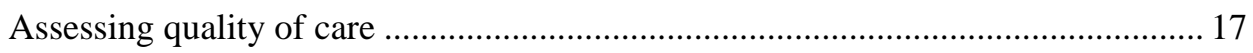

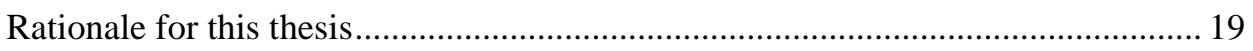

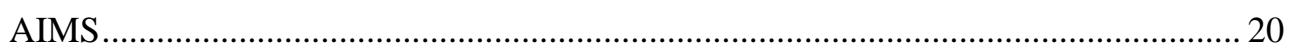

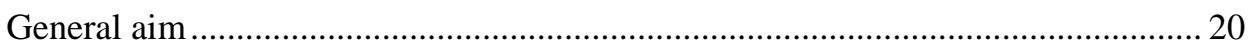

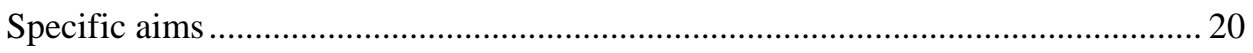

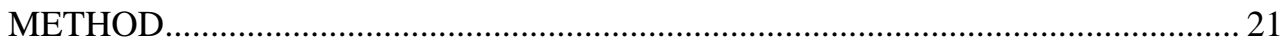

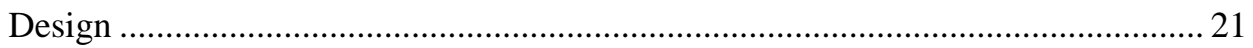

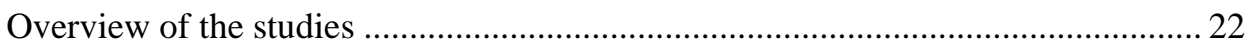

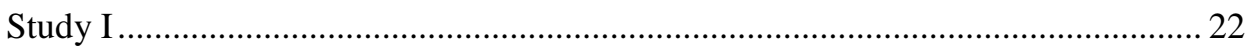

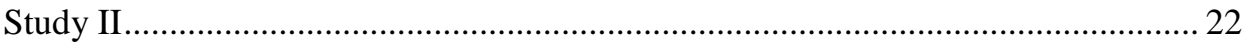

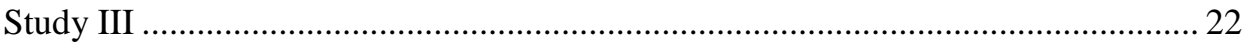

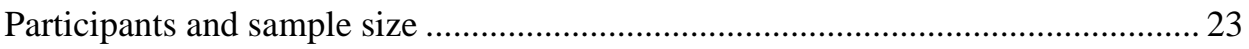

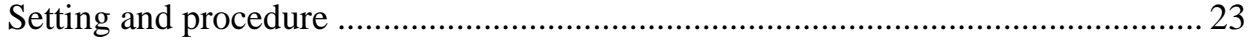

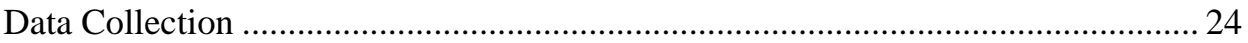

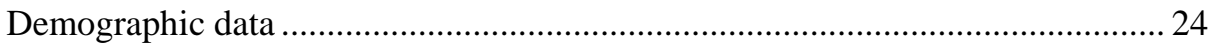




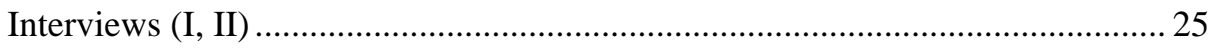

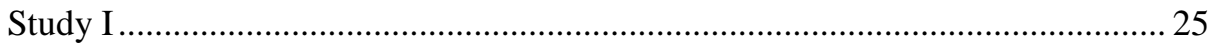

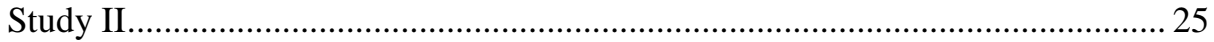

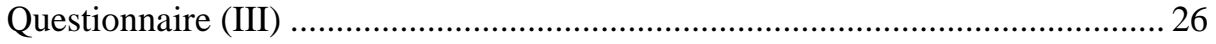

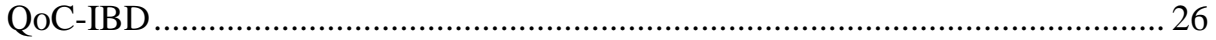

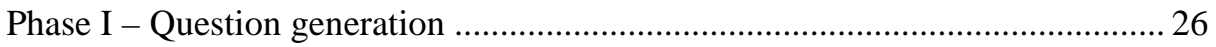

Phase II - Patients’ and professionals’ evaluation.......................................... 27

Phase III - Measurement evaluation ..................................................................... 28

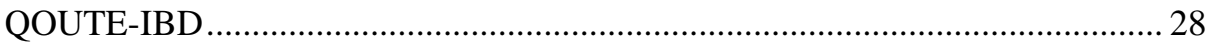

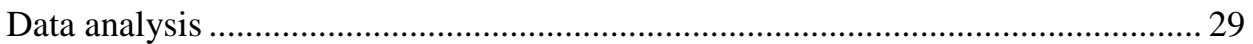

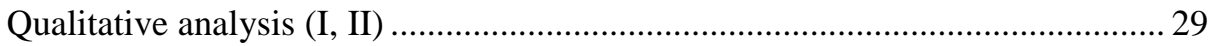

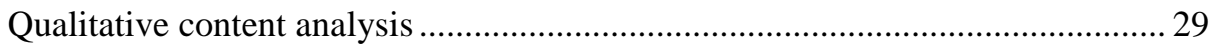

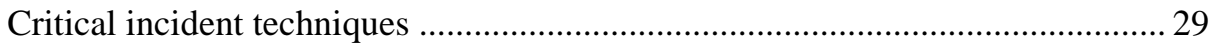

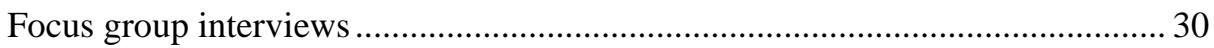

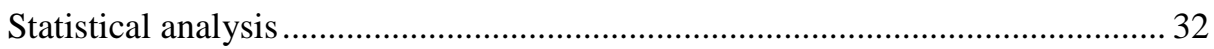

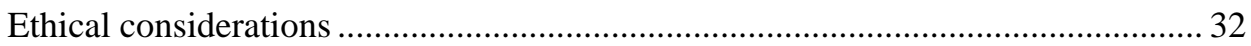

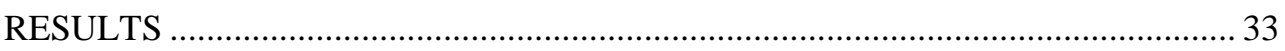

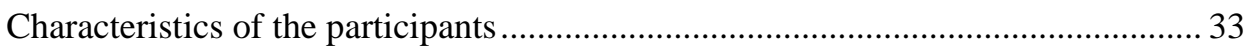

When daily life becomes affected by symptom burden......................................... 33

The importance of disease related knowledge .................................................... 34

Being met with trust and respect........................................................................ 35

Being an active part of healthcare decisions...................................................... 36

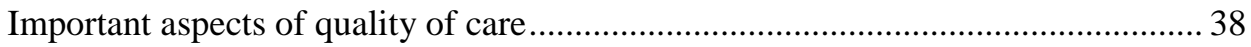

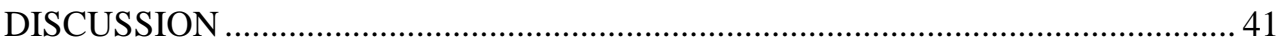

When daily life become affected by symptom burden ....................................... 41

The importance of disease related knowledge ..................................................... 41

Being met with trust and respect...................................................................... 43

Being an active part of healthcare decisions ....................................................... 44

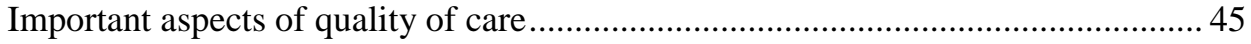

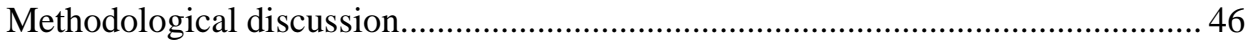

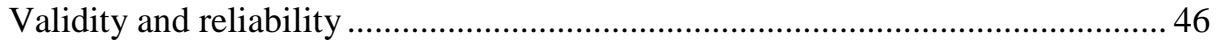

Drop out and question non response study IV .............................................. 48

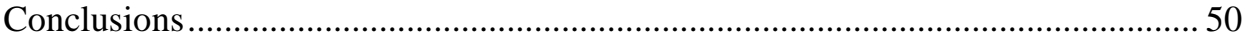

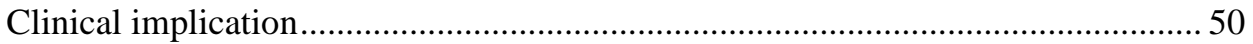

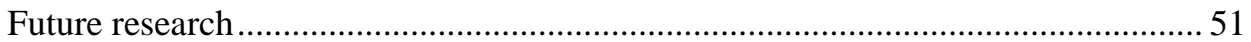


POPULÄRVETENSKAPLIG SAMMANFATTNING 52

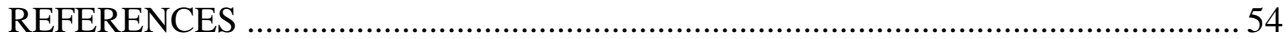




\section{ABSTRACT}

Living with inflammatory bowel disease (IBD) affects physical, psychological and social dimensions, limiting the ability to engage in daily activities. The at times debilitating symptoms create situations that may involve constant consideration of the limitations. To be able to live the life they want and enjoy as good health as possible, persons with IBD may need frequent and lifelong contacts with healthcare services (HC), highlighting the importance of quality care. High quality $\mathrm{HC}$ for persons with IBD involves a partnership between the $\mathrm{HC}$ professionals and the person living with the disease. In order to manage and accept the disease, information is essential. The more a person knows about their disease, the more adherent and satisfied with their treatment they are likely to be.

The overall aim of this thesis was to describe the knowledge need, life situation and perception of $\mathrm{HC}$ among persons living with IBD, in order to develop a questionnaire to evaluate the quality of $\mathrm{HC}$.

This thesis is based on three studies presented in four papers. Qualitative methods were used to describe aspects of life situation in relation to the disease, whereas a quantitative method was used to develop a questionnaire measuring quality of care. Study I and II have an inductive qualitative design. In study I, qualitative interviews with 30 persons were performed to describe the knowledge need and experience of critical incidents in daily life while living with IBD. The interviews in study I were analyzed using content analysis (results presented in Paper I) and critical incident technique (results presented in Paper II). In study II, the perceptions of HC among persons living with IBD was explored in five focus group interviews and two individual interviews, in total $n=26$. Study III aimed to develop and evaluate a questionnaire measuring quality of care among persons with IBD, including 318 persons with IBD and 8 professionals. The knowledge need among persons with IBD focused on managing symptoms and course of the disease and learning to assimilate the information in order to manage everyday life. Losing bowel control was of great concern for most of the informants in the study. Many of the informants said that "the bowel ruled their lives" and that it had a great impact on them. The perception of HC among persons with IBD included being met with respect and mutual trust, receiving information at the right time, shared decision-making, competence and communication, access to care, accommodation, continuity of care and the pros and cons of specialized care. 
The quality of care questionnaire QoC-IBD was constructed in five dimensions, building on the results from Study I and II. The dimensions are trust and respect, decision-making, information, continuity of care and access to care. There are 21 questions in total. The QoC-IBD is a short, self-administrated questionnaire that measures experiences of healthcare among persons with IBD with promising validity and reliability.

To improve quality of care, $\mathrm{HC}$ is recommended to consider individual care needs and take the person's daily life and social context into account. To create a partnership between patients and $\mathrm{HC}$ professionals, the patients need to be involved in decisions that optimize and match their personal care preferences. This knowledge led to the development of the QoC-IBD. The QoC-IBD questionnaire measures the subjective experience of quality of care and was developed in close cooperation with patients to really capture their perception of the quality of care. Further testing in clinical practice is necessary to evaluate if the QoC-IBD can be used to evaluate the care given and identify areas of improvement in $\mathrm{HC}$ for persons living with IBD.

Keyword: critical incident, Crohn's disease, inflammatory bowel disease, knowledge need, life situation, perception of healthcare, quality of care, ulcerative colitis. 


\section{LIST OF PAPERS}

This thesis is based on the following papers, which will be referred to by their roman numerals.

I. Lesnovska KP, Börjeson S, Hjortswang H, Frisman GH. (2013) What do patients need to know? Living with inflammatory bowel disease. Journal of Clinical Nursing, 23(11-12):1718-25.

II. Pihl Lesnovska K, Hollman Frisman G, Hjortswang H, Börjeson S. (2016) Critical situations in daily life as experienced by patients with inflammatory bowel disease. Gastroenterology Nursing, 39(4): 195-203.

III. Pihl Lesnovska K, Hollman Frisman G, Hjortswang H, Hjelm K, Börjeson S. (2017) Healthcare as perceived by persons with inflammatory bowel disease - a focus group study. Journal of Clinical Nursing: doi:10.1111/jocn.13740. (Epub ahead of print).

IV. Pihl Lesnovska K, Börjeson S, Hollman Frisman G, Hjortswang H, Wenemark M. The Quality of Care Questionnaire - development of a valid measure for persons with inflammatory bowel disease. Submitted

Published articles have been reprinted with the permission of the copyright holder. 


\section{ABBREVIATIONS}

IBD

CD

UC

$\mathrm{HC}$

HRQoL

MDT

PSC

QOUTE-IBD

QoC-IBD

NIVEL

IOM

WHO

CFA

WMA

IPAA

JAKs
Inflammatory bowel disease

Crohn's Disease

Ulcerative Colitis

Healthcare

Health- related quality of life

Multidisciplinary team

Primary sclerosing cholangitis

Quality of care through the patient's eyes - Inflammatory bowel disease

Quality of care questionnaire in inflammatory bowel disease The Netherlands Institute for Health Services Research The Institute of Medicine The World Health Organization Confirmatory factor analysis The World Medical Association Ileal pouch anal anastomosis Janus kinases selective 


\section{ACKNOWLEDGEMENTS}

I would like to express my sincere gratitude to all who have supported me in different ways during my journey to complete this thesis. Special thanks to:

All participants, in the studies for sharing your time with me. Many life stories have been entrusted to me and touched me in so many ways. Thank you!

Sussanne Börjeson, my main supervisor, for your enormous amount of enthusiasm and patience when you guided me on this scientific journey. You have allowed me to find my own scientific path, which made me grow.

Henrik Hjortswang, my co-supervisor in research and supervisor in clinical practice. I value your clinical wisdom and humble attitude.

Gunilla Hollman Frisman, my co-supervisor for your enthusiasm, support and energy. Your eagle eye has been valuable in finding all my misspelled words.

Katarina Hjelm, my co-author, for valuable scientific knowledge in qualitative research.

Marika Wenemark, my co-author for explaining statistics and questionnaire development.

Mats Fredriksson, for valuable statistical advice in study III.

J enny Sjödahl, for valuable comments and feedback on my research.

Linda Hermansen, for helping me out when my computer and I disagreed.

Kristina Bogren, my former supervisor for pushing me in the right direction. Otherwise, this thesis would never have been written.

All doctoral colleagues, post docs and staff at the Division of Nursing Science (IMH and ISV), for valuable discussions and comments during our seminars. Special thanks to Sofia McGarvey for valuable language editing.

All colleagues at the Department of Gastroenterology and Hepatology for being patient with me all these years. A special thanks to all colleagues' at the Endoscopy unit, BFE and IBD team, Lotta Granberg, Malin Björk, Emelie Ljungström, Anna Kullberg, Helena Ekstrand, Karin Fridell, Britt Brage, Berit Kindvall Nilsson and the liver team, Helen Hernandez and Carola Fagerström.

Ferring, Abbvie, FSGS, MSD and Region Östergötland, for funding parts of my studies.

Rikard Svernlöv and Ann Lundberg, for being patient with me in the "klinikledning" during all these years and for being my colleague and friends. 
My IBD sisters, all around Sweden, A special thanks to Susanna J äghult, Ann Tornberg and Eva Blackås.

All my friends and relatives, for making me think of other things than research. I am thankful for all dinners, coffee breaks, power walks and travels with you. Special thanks to: Sara A, Tommy and Monika, Anna and Tomas, Bozo and Madeleine, Karro and Tobbe, Kristina and Oskar, J ocke and Rakka, Cecilia, Therese, J ohanna, Anna, uncle Hasse and aunt Bathma, and many more.

My father, for raising me to who I am. You have always believed in me, I love you!

Majka Vidanka and tatko Krste, you have supported me in so many ways that words are not enough to express my gratitude. Ve sakam!

Anna Karin, my beloved little sister and her family for being there whenever I needed you, my second family! I love you all!

Izabelle, Oliver and my precious little Stella, you are everything life is worth living for. Thank you for all the joy and love you bring to my life - I love you so much. "Bosse" is done with this journey now, and will set new goals.

Aleksander my darling husband, for all your love and understanding. You are the one who knows me the best, and still love me for who I am - I love you to the moon and back. 


\section{INTRODUCTION}

Persons with inflammatory bowel disease (IBD) have to manage a lifelong condition. Living with IBD is unpredictable and may influence several aspects of life (1).

The following text is an extract from one of the interviews in this thesis and describes the life situation when living with IBD.

'I was still at school when I became ill. I was 12, that's more than 50 years ago, and it was quite an unusual illness then. They didn't know as much about it then. All of a sudden, I lost a lot of weight, started bleeding a lot and had frequent diarrhea. I couldn't get out the door even though they tried to force me to go to school. I was admitted to a specific type of ward where they did all the examinations. I was in the same room as the adults, despite being so young, because I was nearly as tall as I am now although I weighed close to nothing. They couldn't fit me in the children's ward because I was too tall. I spent a great deal of my childhood in hospital. I remember being there over Christmas, I think my mom came to see me occasionally. My dad didn't, because he found it too hard. In addition, my parents ran a company each and they had four children of whom I was the oldest.

All those examinations, I remember having a really high temperature and they needed to examine my stomach and take X-rays. I shudder when I think about all the injectable contrast I had to take. And there were real enemas to flush out the intestines. I didn't know what was going to happen and no one told me. They just carried on with the examinations. For some, they needed to use physical violence. It was really tough. I asked loads because I was curious while at the same time shy and scared, but I never received any answers.

I had to stay in hospital for a long time. I had to go and get my own food at some kind of hospital restaurant, but I couldn't do it and fainted instead, and I seem to remember that some other patients helped me. My blood count was really low, so I got dizzy. No one realized how ill I was. Or perhaps they did, but they never told me in case I'd worry. Being really ill and more or less growing up in hospital affects you more than you might think. Perhaps that explains why my body aches so much these days. And I don't care for my mom to this day, but I am very fond of my dad".

People living with a chronic illness such as IBD are dependent on a collaborative process, involving mutual understanding between the person living with the disease and healthcare professionals, development of a care plan, self-management, and follow-up contacts (2). 
More attention has been drawn to the quality of the delivered care for persons with chronic illness and there has been an increasing effort in improving the quality of care (3).

In the last few decades, the medical progress has been prominent, with new therapies that will potentially revolutionize treatment strategies for persons with IBD (4). However, although a wide array of drugs have been, and are still being developed, (4) HC providers sometimes tend to focus on treatment and symptoms and forget to listen to the subjective aspect of living with IBD. Persons living with a chronic disease such as IBD require information and support from the HC in order to deal with everyday life.

Due to the complexity, heterogeneity, costs, patient impact and lifelong nature of IBD, the illness should ideally be managed by a multidisciplinary team (MDT) including a number of professions (2). Research on IBD and MDT has provided recommendations on the composition of an IBD team (3). The core team should include IBD specialist nurses, a nutritionist, a gastroenterologist, an endoscopist and a surgeon (3). It seems obvious to include the patient in the MDT, but no literature has been found to support this concept in IBD.

This thesis originated from a number of clinical questions. While I was working at the ward caring for persons with IBD, and the more experienced I became as a nurse, the more I realized that these patients need nursing support to be able to manage their life situation. Part of my master's degree in nursing science consisted of a study identifying and describing the meaning of quality of life to persons with Crohn's disease (CD). The experience of quality of life was associated with limitations in daily activity. Moreover quality of life varied, depending on how the persons managed limitations related to the symptoms of the disease. One conclusion was that it is important to identify limitations and provide support so that patients are able to maintain a daily life where each and every one is able to do the most important activities to them and achieves their goals in life (5). I became curious about questions such as whether $\mathrm{HC}$ professionals provide persons with IBD with the information they want, and what the actual need for information might be. What is the most critical issue when living with IBD? How should HC professionals' best support persons living with IBD to manage these situations? Other questions dealt with how persons living with IBD perceive $\mathrm{HC}$, what quality of care means to them and whether they perceive that HC professionals focus on the right things? 


\section{BACKGROUND}

\section{Historical background}

IBD comprises ulcerative colitis (UC) and Crohn's disease (CD). The two diseases involve the gastrointestinal tract and are characterized by alternating periods of remission and relapses $(6,7)$. IBD is a lifelong disease and to date there is no cure. Descriptions of bloody diarrhea date back to antiquity (8) and in the latter part of the 18th century Matthew Baillie's suggested that patients were dying from UC (8). In 1859 the first "impact" description of UC by Samuel Wilks concerned a 42- year- old woman whose autopsy demonstrated a transmural ulcerative inflammation of the colon and terminal ileum, originally designated as "simple ulcerative colitis". A century later this was, however, identified as CD (9). A case report by Wilks and Moxon in 1875 describing ulceration and inflammation of the entire colon in a young woman describes an early incidence of UC (9). European care reports of CD in the early 20th century, have documented the occurrence of a similar condition. By 1920 American physicians were reporting similar clinical features: young patients often operated upon for appendicitis, symptoms such as fever, abdominal cramps, diarrhea, and weight loss. The disease usually involved the terminal ileum or ileocecal area (10). At the American Gastroenterology meeting in 1932, the American pathologist Burrill B. Crohn and coauthors compiled for the first time the complete histological and clinical picture of terminal ileitis, and how the disease manifests itself. Later on the disease was referred to as "Crohn's Disease" (10).

\section{Diagnosis}

Diagnostics of IBD currently relies on symptoms, the detection of inflammatory changes macroscopically and histologically, and the exclusion of infectious or other differential diagnoses (11). Crohn's' disease is a transmural segmental inflammation that can affect any part of the gastrointestinal tract, from mouth to anus, while UC is a continuous homogenous inflammation involving the rectum and to various extent the colon, but no other parts of the gastrointestinal tract $(6,12)$. Most of the histopathologic findings in UC are limited to the mucosa and superficial submucosa with deeper layers unaffected except in severe disease where the deeper layers are also affected (11). In CD, the macroscopic findings of endoscopy are discontinuous lesions of ulcers or deep linear mucosal ulcers, cobblestone formation of mucosa, thickened bowel wall and luminal narrowing (11). Laboratory biomarkers can be used in the diagnosis and management of IBD, but none have been proven to be optimal. 
More efforts are being made to discover new biomarkers that can discriminate between the types of IBD, predict future responses to treatment, and aid in differential diagnosis, treatment planning, and prognosis prediction (13).

\section{Course of the disease and symptoms}

The most common symptoms in IBD are diarrhea, urgency, tenesmus, rectal bleeding and/or mucus, abdominal pain, weight loss, fever and fatigue (14). The clinical spectrum of IBD is very wide and ranges from an asymptomatic quiescent state to a life-threatening illness (14). The long-term course of IBD is often characterized by symptomatic flare-ups and intermittent periods of remission. Crohn's disease often has a more progressive course, with complications from ulcerations and strictures that may result in abdominal or perianal fistulous tracts, abscesses and intestinal obstruction (6).

The course of the disease is reported to be highly variable, but there are still relatively limited data available on the natural history of IBD from populationbased studies. The cumulative relapse rate after living with UC for 10 years is $83 \%$. The cumulative colectomy rate after 10 years is $9.8 \%$ overall and $19 \%$ in patients with initial extensive colitis (15). During a ten-year period, $28 \%$ of persons with $\mathrm{CD}$ underwent surgery with intestinal resection. Half of these diseases were localized in the terminal ileum. At the time of diagnosis 15-27\% had ileitis, $42-45 \%$ colitis and $26-37 \%$ ileocolonic CD $(16,17)$. Fourteen percent of the patients had a relapse-free 5 -year course (15). As most patients have a relapsing course and most CD patients develop complications, there has been much focus in recent years on the determination of important predictive factors (18).

\section{Pathogenesis}

The underlying pathogenesis of IBD remains uncertain. The etiology is believed to be multifactorial, and associated factors mucosal barrier dysfunction, gut microbiome immune dysregulation that is triggered by environmental stimuli, and genetic predisposition (12). To date, 200 genetic loci have been associated with IBD via large-scale genome-wide association studies (19). Together, these loci explain $13.1 \%$ and $8.2 \%$ of variance in disease liability in Crohn's disease and ulcerative colitis respectively (19). However, no single gene has been identified explaining exactly why some individuals develop IBD (11). Knowledge of epigenetic mechanisms may explain the influence of environmental factors and the microbiota on IBD (12). There are also environmental risk factors, such as smoking, appendectomy, diet, infections, nonsteroidal anti-inflammatory drugs (NSAID) and antibiotics (20, 21). 


\section{Epidemiology}

IBD occurs worldwide, but has a varying incidence and prevalence. The annual incidence of UC varies between 0.6-24.3 cases per 100,000 inhabitants in Europe, 0.1-6.3 cases per 100,000 inhabitants in Asia and the Middle East, and 0-19.2 per 100,000 in North America (22). For CD, the estimated incidence ranges from 0.3-12.7 per 100,000 in Europe, 0.04-5.0 per 100,000 in Asia and the Middle East, and 0-20.2 per 100,000 in North America (22). The incidence of IBD is currently increasing in areas where the disease was previously infrequent. As a result, the gap between high and low incidence countries is closing (23).

\section{Associated health problems}

About one third of persons with IBD develop additional extra intestinal symptoms involving other organs than the gastrointestinal tract. The most common extra intestinal symptoms occur in the skin (erythema nodosum, pyoderma gangranosum), joints (entheropathic arthropathy, sacroilitis, ankylosing spondylitis), hepatobiliary tract (primary sclerosing cholangitis, autoimmune hepatitis), and eyes (uveitis, conjunctivitis) (24). Primary sclerosing cholangitis (PSC) is a chronic IBD- associated hepatobiliary disease with a prevalence of $1.4-3.5 \%$ in $\mathrm{CD}$ and about $2-7.5 \%$ in UC, predominantly among persons with total colitis (25). PSC is frequently diagnosed between the third and fifth decades of life, with a 2:1 male predominance (25). Patients with PSC are at risk of a malignant transformation of the bile duct and in the colorectal tract, which makes this group of patients important to monitor (25). Malnutrition and micronutrient deficiencies are reported in 20-50\% of persons with CD (26). Women with IBD have fertility rates similar to the general population prior to surgery. However, after surgery for an ileal pouch anal anastomosis (IPAA), fertility rate is decreased $(27,28)$. Among the IPAA patients, infertility occurs before diagnosis of UC in $13.6 \%$, after diagnosis but before surgery in $6.7 \%$, and after IPAA in $79.7 \%$ (28). The offspring of patients with IBD are more likely to have IBD than the general population. The prevalence of a family history of IBD is significantly increased in first-, second, and third-degree relatives of persons with IBD, with up to $12 \%$ of all IBD cases being family cases (29).

\section{Treatment}

Before treatment was available, the relative risk of dying from IBD was increased (30). The cumulative mortality rate was $30 \% 15$ years after diagnosis in the $1950 \mathrm{Os}$ (31). Mortality has declined and nowadays, the overall mortality is no different to that of the background population (32). Treatments were previously based on a wide range of different diets and surgical procedures (30). 
As there is no cure for IBD, the main goal for medical treatment was to induce and maintain remission(14). The first effective drug Sulphasalazine was introduced in the 1940s, and its use can be attributed to the Swedish professor Nanna Svartz (33). Steroid treatment was established in the 1950s (30). Treatment choice depends on inflammatory activity, disease location, and previous treatment response. Traditionally a "step-up" approach of adding therapies is used, but it has been suggested that a "top-down" strategy has more advantages in cases of more severe disease $(34,35)$. Maintenance treatment in UC generally includes drugs such as amino salicylates(34). Treatments effective for inducing remissions include corticosteroids and amino salicylates. Immunosuppressive treatment with thiopurines (6mercaptopurin, azathioprine) and biological immunosuppressive therapies (anti-TNF, anti-a4 $\beta_{7}$-integrin, and anti-IL12/23) have emerged as efficient therapy options in more severe disease. For patients not responding to medical treatment or suffering from intestinal complications such as colonic dilatation, perforation, dysplasia, stenosis, abscesses or fistulae, surgery should be considered (34-36). There is a large number of ongoing studies in various stages of research on new molecules for treatment of IBD that are expected to change the course for treatments. Small molecules such as tofacitinib, a nonbiologic oral inhibitor of Janus kinases (JAKs) selective for JAK1 and JAK3, hold promising results with a tolerable safety profile $(37,38)$.

\section{Impact on life situation}

The often unpredictable symptoms of IBD can have a profound effect on the individual's life situation. Living with the disease can be stressful in itself and potentially contribute to difficulties in coping with other demands as they arise (39-41). There is a high prevalence of psychological distress such as anxiety among persons with IBD (42-44). Disease severity, illness perceptions, maladaptive coping, stress, anxiety, depression and quality of life seem to be related (45). Individuals who experience greater disease severity seem to generate poorer illness perceptions, more often have maladaptive coping strategies, suffer from stress and pressure to a greater extent, experience higher levels of psychological problems such as anxiety and depression, and have a lower health- related quality of life (HRQoL) $(45,46)$.

Individuals enduring more symptoms might generate more pessimistic cognitions of their disease and think about their condition with more hopelessness. The severity of the flare-up and the frequency of relapses intensely affect lifelong well-being in persons with IBD (47). Illness perceptions have been shown to directly influence stress suggesting that poorer illness perceptions could increase mental and emotional tension(44). 
Illness perceptions may also influence anxiety, depression and quality of life. Thoughts about having a chronic disease, that cannot be controlled and that has complex consequences have been shown to lead to high levels of psychological distress and reduced HRQoL $(44,46)$. HRQoL in persons with IBD, and their worries and concerns have been thoroughly investigated $(5,48$, 49). Higher levels of worrying seem to be associated with increased IBD symptoms. In addition, worries about undergoing surgery or having an ostomy bag have been rated the highest among persons with UC, even when IBD symptoms improve. In $\mathrm{CD}$, the top three concerns were ostomy bag, energy level and, loss of bowel control (48).

IBD has been described to negatively affect daily routines, including physical activity, sleep patterns/habits and social outings (50). Most of the stress experienced is related to the lack of control over bowel movements. Therefore, it is an important task for $\mathrm{HC}$ professionals to reduce or control symptoms. Studies have shown that persons with IBD emphasize that symptoms and bowel control are important issues, but that $\mathrm{HC}$ still does not respond fully to these needs $(51,52)$. As a way to prevent social isolation, patients may be encouraged to use coping strategies such as planning and preparation to facilitate participation in social activities. Coping strategies used by patients include, informing their network about the disease, accepting the disease and staying positive $(50,53)$. IBD significantly affects all aspects of a person's life - education, work and social life. For example, a recent international survey found that around half of all patients felt that their career prospects had been negatively affected. Almost the same number of people said that IBD had hindered them in their personal life and relationships (51). One consequence of IBD is a reduced ability to work or study $(54,55)$. A tenyear follow-up study showed that an increased risk for disability pension was associated with being diagnosed at a young age (under 30 years of age at the time of diagnosis), steroid treatment one year after diagnosis, colectomy during the first year and more than two relapses during the first year (56). Women with $\mathrm{CD}$ have the highest rate of disability pension among persons with IBD, although no study has been able to show that the clinical course of the disease in $\mathrm{CD}$ is more severe in women than in men (56).

Various forms of support and information, in groups or individually, have been requested by persons with IBD. It has been stressed that educational interventions should be provided by a MDT (2). Educational interventions should fit the individuals' needs and be offered at times when they are needed, that is, in recently diagnosed patients and during episodes of flare-ups (57). 
However, in $\mathrm{HC}$ there is a knowledge gap regarding the situations that are the most critical for persons living with IBD. There is a need for a deeper understanding of limitations and critical incidents in daily life. To manage these situations, persons with IBD need knowledge on symptom recognition, how to handle symptoms, plan their lives and seek new options (57). Some persons with IBD do not have sufficient knowledge to manage or recognize symptoms of flare-ups, which in turn can lead to them delaying seeking care during a relapse (57).

\section{Disease related knowledge}

Acquiring knowledge is a complex cognitive process of perception, learning, communication, association and reasoning closely associated with health behavior. According to social cognitive theory, processes entailed in regulating one's health can be taught through social modeling, supports, and feedback $(58,59)$. The area of information exchange in $\mathrm{HC}$ has been thoroughly studied in terms of, for example, research on lack of health literacy (60), dissatisfaction with the amount of information received (61), failure to remember information, and lack of understanding the perspective of the person living with the disease $(62,63)$. Research in the area of knowledge and IBD has been focused on measuring the amount of knowledge (64-66) rather than studying the actual need for knowledge among persons living with IBD.

Persons with chronic diseases must navigate through a complex HC system to obtain care from the time when they start having symptoms and throughout their whole lives. For persons living with a chronic disease, it is essential to have disease related knowledge in order to be able to manage and accept the disease (67). Most want to know all about their disease and treatment options but yet many may become overwhelmed by the sheer volume of information (68).

The terms knowledge and information are often used more or less interchangeably, although there are obvious differences. In this thesis, knowledge is defined as information that is given meaning and understanding to be applied in different situations, in this case, by persons living with IBD. Factual information that is not placed in a specific context is defined as "information". Information needs to be interpreted and given a context to become knowledge (69). It is important to give some thought to how information is to be given to a person. This requires an understanding of how each individual acquires knowledge (63). 
$\mathrm{HC}$ professionals need to be aware of the questions and concerns of persons with IBD and they have to be capable of providing the information in a clear and concise manner (63). Patients with chronic diseases such as IBD require an information exchange with a HC professional in order to achieve diseaserelated knowledge. Knowledge about the disease can play a critical role in facilitating a person's acceptance of their illness and understanding of behavioral changes, in order to actively participate in treatment and the development of a better caregiver-patient relationship (65). A great part of persons with IBD feel insufficiently informed about their disease (70). A low level of knowledge combined with poor social support is associated with a greater impairment in HRQoL (71). Schwarz and Blanchard (1991) showed that a combination of IBD-related education and individual behavioral treatment reduced IBD symptoms and IBD-related stress (72). Larsson et al. (2003) reported an improvement of satisfaction with IBD-related information in a group-based educational program for persons with IBD suffering from high levels of anxiety. However, there was no improvement of HRQoL (73). A study evaluating a group based intervention program showed a correlation with increased HRQoL among patients with short disease duration (74). A low level of disease related knowledge seemed to correlate with more worries and concerns, whereas a high level of disease-related knowledge seemed to increase compliance (71). Moreover, it was shown that suitable education improves patients' treatment and coping methods and reduces their anxiety (66). Disease related knowledge seemed to reduce the number of appointments with physicians and, consequently, lower patient costs (66).

In a study from 1987 by Scholmerich et al., aiming to identify fear factors among patients with IBD, patients were asked to fill in a questionnaire containing 36 questions and 9 "fear factors"(75). The most important questions selected were remission of their disease, and developing cancer. Women deemed questions regarding cancer, sex life, side effects of diagnostic techniques or drugs to be important more often than men. The latter were more interested in the cause, symptoms and natural history of the disease (75). In 2008, the consensus on patient quality of care by the European Crohn's and Colitis Organisation - ECCO- recommended delivery of patientcentered information to meet patients' needs. However, it does not specify how information should be provided (76). In 2002, Kennedy et al (77) aimed to develop patient information that would engage $\mathrm{HC}$ professionals in shared management. The study identified a significant gap between the patients' and professionals' opinion on need for information. Patients wanted information that was supportive (77). 
They were concerned about how they would be affected by UC and, consequently, in finding out about other people's experiences. In contrast, doctors expected information to increase adherence and help patients make better use of $\mathrm{HC}$ services. This finding suggests a conflict between patients' need for alternative knowledge and a tendency for doctors to retain a preference for information about traditional management strategies (77). It can be concluded that interventions aiming to increase the knowledge have not led to an improvement in HRQoL so far (74).In addition, a low level of disease related knowledge seems to correlate with increased worries (73). Patients seems to be willing to become more involved in their $\mathrm{HC}$ and understand the full consequences of any actions they take (75).

In this thesis, the focus is on the need for knowledge among persons with IBD, in order to understand the variety in individual knowledge need. Furthermore, we wanted to investigate the time point in the disease process at which knowledge is needed.

\section{Quality of care}

In 1980, Donabedian described high-quality care as the kind of care that is expected to maximize an inclusive measure of patient welfare, after one has taken into account the balance of expected gains and losses that occur throughout the process of care (78).

The American Medical Association has defined high-quality care as care that consistently contributes to the improvement or maintenance of quality. They identified specific attributes of care that should be examined when determining its quality, including health promotion and disease prevention, timeliness, the informed participation of individuals, attention to the scientific basis of medicine, and the efficient use of resources. In 1990, the Institute of Medicine (IOM) defined quality of care as "the degree to which health services for individuals and populations increase the likelihood of desired health outcomes and are consistent with current professional knowledge" (IOM, 1991, pp. 21). The IOM concluded that there is a gap between the existing $\mathrm{HC}$ and the care we could have. This report was a call for action demanding accountability of the HC system and implying that system wide changes were necessary to substantially improve care (79).

The World Health Organization (WHO) definition of the concept of quality of care divides healthcare into six different components. These are effective, efficient, accessible, acceptable/patient-centered, equitable and safe (80). 
In Sweden the National Board of Health and Welfare (2009) has confirmed the aspects of good care addressed by the WHO (2006) and uses the same six aspects to describe what characterizes good quality care in a Swedish care context (81). When discussing quality of care, the interaction between the caregiver and caretaker is an important concept. The interaction between them depends on several elements in their relationship, such as the quality of their communication, the HC professional's ability to maintain the patient's trust, and the HC professional's ability to treat the patient with concern, empathy, honesty, discretion and sensitivity (80).

Over the past decade, efforts to improve the quality of care have been made in many parts of the world. In a Swedish context, a model was formulated by Wilde et al. in 1993 (82). According to this model, quality of care can be understood from the resource structure of the care organization and the patient's preferences. The resource structure of the care organization consists of person-related and physical and administrative qualities. The patient's preferences have a rational and a human aspect. Within this framework, patients' perceptions of quality of care may be considered from four dimensions: the medical-technical competence of the caregivers; the physicaltechnical conditions of the care organization; the degree of identity-orientation in the attitudes and actions of the caregivers and the socio-cultural atmosphere of the care organization (82).

An increasing body of evidence has suggested that creating centers of excellence will lead to better quality of care. The types of quality indicators generally used are structural measures. When evaluating quality of care, it is important not to forget the patients perception of the received care, quality of life, and patient satisfaction (83).

\section{Assessing quality of care}

The purpose of measuring quality is to lay the foundation for improving it. Many questionnaires measuring quality of care are typically structured according to a framework originally described by Avedis Donabedian (1980, 1989), who formulated a model according to which patients' wishes can be divided into three general components-structural, process, and outcome measures $(78,84)$. Structural measures are the characteristics of the setting in which care is delivered. Process measures indicate the steps taken by healthcare professionals in the care of an individual patient. Outcome measures describe what happens to patients as a result of the care they receive (78). 
Healthcare professionals have always acknowledged that satisfying patients at some level is essential to provide high-quality care. However, they have often discounted the importance of patients' perspectives in the belief that patients have limited knowledge of what constitutes technical quality. Difficulties measuring patients' views have also played a part (82).

To determine what constitutes good or poor quality, HC must acquire knowledge on how individuals value various health outcomes and how these may differ among individuals. The Netherlands Institute for Health Services Research (NIVEL) has developed a series of questionnaires that measure Quality of Care Through the Patient's Eyes (QUOTE). The QUOTE instruments were developed particularly for chronically ill patients, elderly people, disabled people, and individuals who use specific healthcare services. The QUOTE instruments are based on Donabedian's “structure-process-outcome" characterization of healthcare quality. The QUOTE instrument for persons with IBD, the QUOTE-IBD, includes 10 generic questions and 13 disease specific questions. The questionnaire comprises three categories: Importance, the weight that the patient gives to various care aspects; Performance, experiences regarding the function of medical practices and healthcare professionals for each aspect of care; and Quality Impact, the combined effect of importance and performance (85).

Some studies have been performed on the aspect of quality of care among patients with IBD showing that patients gave relatively poor marks to parts, such as being provided with information and the psychological as well as physical approach (85-87). The existing knowledge about IBD and quality of care is based on studies measuring quality of care with predefined questions $(86,88)$. Results from the QUOTE-IBD studies showed that the lowest importance scores were observed for autonomy, costs and accessibility. The three most important aspects of quality of care for IBD patients were competence, accommodation and courtesy $(86,88)$. In the Portuguese version of the QUOTE-IBD, it was concluded that there is no golden standard for the assessment of quality of care from the perspective of those living with IBD. The need for a shorter and more user-friendly questionnaire was also expressed (89). 


\section{Rationale for this thesis}

Persons with IBD have to manage a lifelong condition that may influence several aspects of life. The care is dependent on a collaborative process, involving a mutual understanding between the person living with the disease and $\mathrm{HC}$ professionals. For HC, it is important to identify knowledge needs, limitations and provide support to maintain daily activities, so that the disease does not hinder the persons with IBD in achieving their goal in life. As a lifelong condition with a significant burden of illness, IBD is particularly suitable for quality of care measurement and improvement. A valid and reliable questionnaire to assess quality of care in IBD is therefore needed.

When this thesis was initiated at the end of 2010, only limited research had been done in the area of quality of care and IBD. In September 2013, there was an initial meeting in Oxford, IBD2020, aiming to become a global forum for discussions on how to best improve the quality of care for persons with IBD. The IBD2020 group agreed that persons with IBD should have access to a recognized IBD multidisciplinary team, including specialist nurses, who can provide them with optimal care, taking into account their physical, emotional and social well-being. All persons with IBD should have opportunities to become more knowledgeable about their disease and the various treatments and support available to them, so that they can, become more actively involved in the clinical decisions of their IBD, if they should wish to $(52,90)$. This is still not the clinical reality for many persons with IBD.

Therefore, this thesis aims to decrease the knowledge gap and give an overview of the life situation for persons living with IBD. The measurement of the subjective experience of quality of care in this thesis provides $\mathrm{HC}$ with important knowledge. This knowledge is needed to develop evidence-based nursing interventions and offer high-quality care for persons with IBD in need of healthcare. 


\section{AIMS}

\section{General aim}

The overall aim of this thesis was to describe the knowledge need, life situation and the perception of $\mathrm{HC}$ among persons living with IBD, in order to develop a questionnaire to evaluate the quality of HC.

\section{Specific aims}

Study I (Paper I): To explore the need for knowledge as expressed by patients diagnosed with inflammatory bowel disease.

Study I (Paper II): To describe how patients living with IBD experience critical incidents in daily life in relation to their disease and symptoms.

Study II (Paper III): To explore the perceptions of healthcare among persons living with inflammatory bowel disease.

Study III (Paper IV): To develop a questionnaire measuring quality of care in persons with IBD. 


\section{METHOD}

\section{Design}

This thesis comprises two qualitative and one quantitative study, resulting in four scientific papers. An overview of the design, participants, data collection, and data analysis is presented in Table 1 . The studies that are included in the thesis will be referred to as study I-III and the papers as paper I-IV.

Different designs and methods were used, based on the aim of the study. Individual interviews were performed to describe the knowledge need and critical incidents among persons with IBD (Study I). Focus group interviews were performed to describe the perception of $\mathrm{HC}$ among persons with IBD (Study II). Finally, a questionnaire was developed from the results of the qualitative studies and tested for validity and reliability (Study III).

Table 1. Overview of designs and methods in the thesis

\begin{tabular}{|c|c|c|c|c|}
\hline & Study I/Paper I & $\begin{array}{l}\text { Study I/Paper } \\
\text { II }\end{array}$ & $\begin{array}{l}\text { Study II/Paper } \\
\text { III }\end{array}$ & $\begin{array}{l}\text { Study III/Paper } \\
\text { IV }\end{array}$ \\
\hline Design & $\begin{array}{l}\text { Qualitative } \\
\text { inductive method }\end{array}$ & $\begin{array}{l}\text { Qualitative } \\
\text { inductive method }\end{array}$ & $\begin{array}{l}\text { Qualitative } \\
\text { inductive method }\end{array}$ & $\begin{array}{l}\text { Questionnaire } \\
\text { development }\end{array}$ \\
\hline Participants & $\begin{array}{l}\text { Persons with IBD } \\
\mathrm{n}=30\end{array}$ & $\begin{array}{l}\text { Persons with IBD } \\
\mathrm{n}=30\end{array}$ & $\begin{array}{l}\text { Persons with IBD } \\
n=26\end{array}$ & $\begin{array}{l}\text { Persons with IBD } \\
\mathrm{n}=318 \\
\text { Group of } \\
\text { professionals } \\
\mathrm{n}=8\end{array}$ \\
\hline $\begin{array}{l}\text { Data } \\
\text { collection } \\
\text { methods }\end{array}$ & $\begin{array}{l}\text { Individual } \\
\text { interviews }\end{array}$ & $\begin{array}{l}\text { Individual } \\
\text { interviews }\end{array}$ & $\begin{array}{l}\text { Focus group and } \\
\text { individual } \\
\text { interviews }\end{array}$ & $\begin{array}{l}\text { Literature overview, } \\
\text { focus group and } \\
\text { expert group, } \\
\text { cognitive interviews, } \\
\text { questionnaires }\end{array}$ \\
\hline Data analysis & $\begin{array}{l}\text { Qualitative } \\
\text { content analysis }\end{array}$ & $\begin{array}{l}\text { Critical incident } \\
\text { technique }\end{array}$ & $\begin{array}{l}\text { Focus group } \\
\text { analysis }\end{array}$ & $\begin{array}{l}\text { Focus group analysis, } \\
\text { qualitative analysis } \\
\text { of cognitive } \\
\text { interviews/individual } \\
\text { interviews. } \\
\text { Confirmatory factor } \\
\text { analysis, Test-retest }\end{array}$ \\
\hline
\end{tabular}




\section{Overview of the studies}

\section{Study I}

A qualitative study designed to explore the need for knowledge and describe the experience of critical incidents in daily life was performed. Thirty persons with IBD were interviewed. Content analysis was used to analyze the need for knowledge (91) and the results are presented in paper I. The experience of critical incidents in daily life was analyzed with critical incident technique (92) and the results are presented in paper II.

\section{Study II}

A qualitative explorative study was performed to explore the perception of $\mathrm{HC}$ among persons living with IBD. Five focus group interviews and two individual interviews were conducted with 26 persons with IBD. The focus group interviews were analyzed using a qualitative method according to Kruger (93) and the results are presented in paper III.

\section{Study III}

A developmental study was performed to develop and test a questionnaire measuring quality of care among persons with IBD. In the development and evaluation, 318 persons with IBD and 8 professionals participated. The results of study III are presented in paper IV. 


\section{Participants and sample size}

In study I, 30 persons with IBD were included and interviewed, 14 men and 16 women aged 29-83 years (md 45 years) (Table 2). The selection was made to ensure maximum variation in age, sex, diagnosed CD and UC, duration of IBD, and history of previous surgery.

In Study II, purposive sampling was used to obtain a wide variation in perceptions of HC. The sample size was five focus groups with three to seven participants in each group, and two individual interviews. A total of 26 persons diagnosed with IBD, fourteen men and twelve women, aged 19-76 years (md 62 years) participated (Table 2).

In study III, a sample size of 600 adults with IBD who had received care at the gastroenterology department at a university hospital in the south-east of Sweden between September 2014 and September 2015, were invited to participate in the study. The sample size of 600 people was based on the 1,242 IBD patients who had contacted the clinic in the previous year. It was decided to invite 600 patients due to the expected response rate of 50\% (94). Approximately 300 participants were considered an appropriate number to be able to analyze differences between subgroups, such as gender, age and diagnosis (UC and CD). From the list of 1,242 patients, there was a random sampling of 300 patients with $\mathrm{CD}$ and 300 with UC.

\section{Setting and procedure}

All studies were performed at a university hospital in south-east Sweden that provides care for 1,700 persons with IBD. In study I, purposeful sampling was made by the main investigator (KPL). Information about the study and a request for participation were sent by postal mail. After receiving written information about the study, the participants were contacted by telephone by the main investigator to arrange a time and place for the interviews. The main investigator conducted 27 interviews in a room at the hospital and three in the participants' homes in accordance with their wishes.

In study II, the main investigator provided the participants with information about the study. Those who agreed to participate returned their written informed consent in a pre-paid envelope and were contacted to arrange a time and date for the interview. All focus group interviews took place in a conference room. The individual interviews $(n=2)$ took place in a room at the ward where the patients currently received care. 
In order to develop and evaluate the questionnaire in study III, focus group interviews, individual interviews and cognitive interviews were used. In total, 318 patients who had received care at the gastroenterology department at a university hospital in south-east Sweden between September 2014 and September 2015 participated in study III. In the development phase, 24 patients participated and in the evaluation phase there were 294 participants.

\section{Data Collection}

Demographic data

Demographic data for the participants in studies I and II were obtained during the interviews (Table 2). In study III, participants with IBD filled out a studyspecific questionnaire with basic demographic data such as sex, age, and type of IBD (Table 2).

Table 2. Demographics of participants with IBD in study I, II, and III

\begin{tabular}{llll}
\hline Variable & Study I/Paper I, II & Study II/Paper III & Study III/Paper IV \\
\hline Participants (n) & 30 & 26 & 318 \\
$\begin{array}{l}\text { Female (n) } \\
\text { Male (n) }\end{array}$ & 16 & 12 & 171 \\
$\begin{array}{l}\text { Age (yrs (range)) } \\
\text { Ulcerative colitis }\end{array}$ & $29-83$ & 14 & 147 \\
(n) & $19-76$ & $18-88$ \\
$\begin{array}{l}\text { Crohn's Disease } \\
\text { (n) }\end{array}$ & 18 & 16 & 155 \\
$\begin{array}{l}\text { Unclassified IBD } \\
\text { (n) }\end{array}$ & 10 & 153 \\
\hline
\end{tabular}




\section{Study I}

The main investigator conducted all interviews $(n=30)(I)$. Two pilot interviews were conducted to test the interview questions included in the study. The interviews lasted for a mean of 40 minutes (range 14-67 minutes). All interviews were digitally recorded. The interviews were held between July and December 2010. The interviews started with one open-ended question (I): Could you please describe your knowledge needs related to living with IBD? Probing questions were asked to encourage the patients to elaborate on and explain their need for knowledge. The next phase of the interviews in study I, which are presented in Paper II, was opened with a broad open question (I): Can you please tell me about a critical incident or situation in daily life related to your disease or symptoms that had consequences for your life and way of managing the disease? Probing questions were used to elicit more details; When/where did it occur? How did you manage the situation?

\section{Study II}

The focus group interviews (five interviews) were held between January and June 2014 (II). The number of participants in each group varied from three to seven. Younger men who were asked to participate did not want to participate in a group interview. To avoid missing out on young men's perception of $\mathrm{HC}$, individual interviews were performed with two younger men instead. A semistructured interview guide with open-ended questions based on the $\mathrm{HC}$ outcome, structure and process (93) was developed by the research team. Interviews were guided by the questions shown in Table 3 .

Table 3. The interview guide used during the focus group interviews and individual interviews in study II

- Please describe how you perceive $\mathrm{HC}$ at the gastroenterology department?

- How do you perceive a good care for a person with your disease?

- What expectations do you have on HC?

- What expectations do you have on HC professionals?

- Based on your disease which needs do you have? 
At the beginning of the interviews, all participants were asked to introduce themselves. Thereafter, the moderator (main investigator) and assistant moderator introduced themselves, explained the purpose of the study and started asking questions. Probing questions were used to elicit more details. Two nurses with experience of qualitative research acted as assistant moderators in two groups and three groups, respectively. The role of the assistant moderator was to support the moderator by asking probing questions, observing the group interaction, making field notes and evaluating the moderators' interviewing technique $(93,95)$. The interviews were digitally recorded. A debriefing with the moderator and assistant moderator took place immediately after each focus group interview, where the moderator's role, the group interaction and any aspects that needed changed were discussed. The first focus group served as a pilot interview (included in the study) (93). The duration of each focus group interview was approximately 1.5 hours and the individual interviews lasted for about 30 minutes. The field notes were used to supplement the transcription during the analysis.

\section{Questionnaire (III)}

QoC-IBD

The development of the Quality of Care questionnaire in IBD (QoC-IBD) was performed in three phases (Figure 1).

Phase I - Question generation

In the first phase, the aim was to generate questions for the questionnaire. A literature review of studies measuring quality of care in IBD was performed in order to identify important aspects related to quality of care (96).

Furthermore, the results from study I and II aiming to identify the knowledge need and perception of $\mathrm{HC}$ among persons living with IBD were used in the generation of questions. The questionnaire was constructed with questions in the following dimensions: trust and respect, decision-making, information, continuity of care, access to care and satisfaction with $\mathrm{HC}$ as a whole. The dimensions were chosen because these areas were stated to be the most important ones for the perception of $\mathrm{HC}$ in study II. The first version of the questionnaire consisted of 24 questions, six in the dimension trust and respect, five in access to care, four in decision-making, three in continuity of care, three in information, two in competence, and one in satisfaction with the care as a whole. For all questions in the questionnaire (except the one on overall satisfaction with $\mathrm{HC}$ ), the respondent was first asked how important the question was to them and then how they experienced the performance. The response options to the performance questions in the first version were "totally agree", "agree to a great extent", "agree to some extent" and "do not agree". 
The response options to the importance questions in the first version were "extremely important", "important", "fairly important" and "not important".
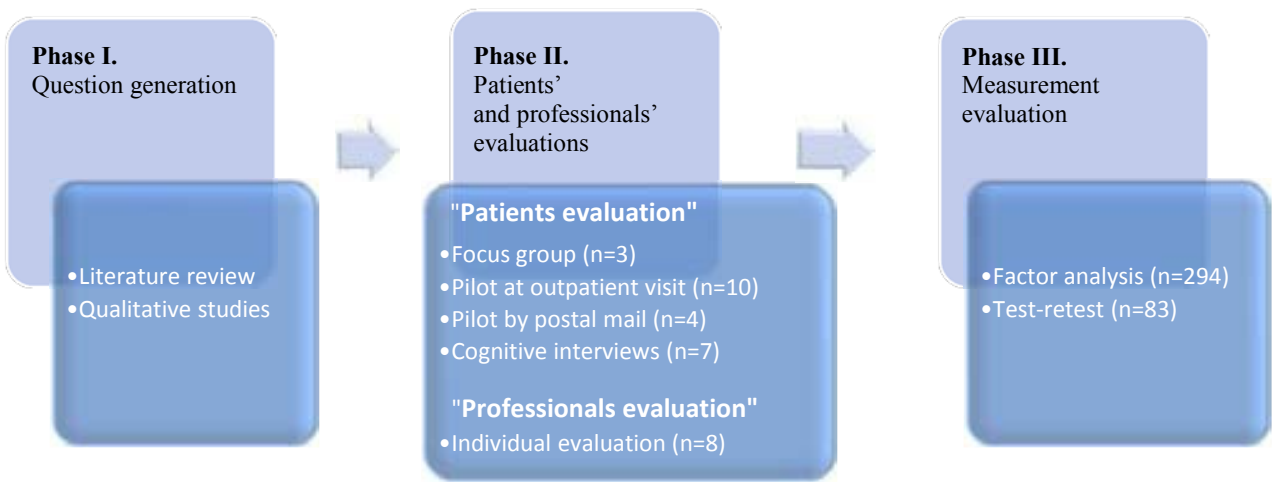

Figure 1. Questionnaire development and evaluation.

\section{Phasell - Patients' and professionals' evaluation}

In the next phase, the aim was to evaluate the first version of the QoC-IBD. The aim of the outpatient pilot was to evaluate the relevance of the questions and the feasibility to answer the questions. In the first step of phase II, the questionnaire was tested in a focus group interview held by the main investigator. The focus group consisted of three patients with IBD, two women and one man of different ages and with different experiences of living with the disease. Thereafter, the questionnaire was pilot-tested by ten patients diagnosed with IBD who had a scheduled appointment at the gastroenterology department. Further on, the questionnaire was pilot tested by mailing it to four patients with IBD who were asked to answer and return it to the main investigator. The aim of the mail pilot was to evaluate the function of the questionnaire when respondents answered it at home without any help or instructions from HC professionals.

The final part of the patient evaluation in phase II was cognitive interviews $(n=7)$ performed by the main investigator and one of the co-authors (MW) in Paper IV. The aim of the cognitive interviews was to evaluate the questionnaire's cognitive function and user-friendliness. The participants in the cognitive interviews were four women and three men with IBD. The interviews were performed according to the method "think aloud" followed by retrospective probes such as "Can you tell me more about..." in order to clarify or explore responses during the interviews (97). 
All interviews were performed in a conference room at the gastroenterology department and lasted between 30 to 60 minutes.

The last part in phase II was an evaluation by a group of professionals $(n=8)$. The questionnaire was sent to professionals familiar with IBD or questionnaire development; three gastroenterologists, two nurses specialized in IBD, one statistician, and two people with experience in questionnaire construction. The questionnaire was sent by mail and the professionals were asked to return their comments and evaluation to the main investigator.

The final questionnaire consisted of five questions about trust and respect, four questions about decision-making, three about information, two about continuity, one question about access to care consisting of six subqueries, and finally one question about satisfaction with $\mathrm{HC}$ as a whole, in total 21 questions. Each question had four response options except for the last question about satisfaction with the care as a whole, which ranged on a scale from 1 to 10.

Phase III - Measurement evaluation

Phase III aimed to test the function of the questionnaire in a real setting and to test reliability and validity. Six hundred patients with a confirmed diagnosis of IBD were invited to participate in the study. Reminders were sent once to nonresponders within a period of four weeks from the first mailing. The participants were asked to fill in the questionnaire and return it in a pre-paid envelope if they gave consent to participate in the study. In all, 294 patients (49\%) returned the questionnaire.

At the end, all participants were asked if they would consider filling in the questionnaire one more time to test reliability. Of the 294 participants 141 agreed to fill in the questionnaire once more and 83 of them returned the second questionnaire within a 2-week span.

QOUTE-IBD

The participants in study III were also asked to answer the QUOTE-IBD. QOUTE-IBD contains questions in eight dimensions; competence, courtesy, accessibility, information, continuity of care, accommodation, autonomy and costs (85). The instrument comprises three response categories: Importance, the weight that the patient gives to various care aspects; Performance, their experiences regarding the function of medical practices and $\mathrm{HC}$ professionals for each aspect of care; and Quality Impact, the combined effect of importance and performance (85). 
The Importance questions are answered by "Not important", "Fairly important", "Important", or "Extremely important". Questions in Performance are answered by: "No", "Not really", "On the whole, yes", or "Yes" (85).

\section{Data analysis}

Qualitative analysis (I, II)

All interviews were transcribed verbatim by the main investigator or by an experienced secretary. The interviews transcribed by a secretary were validated by the main investigator by listening to the audio-recordings and comparing them with the transcribed text. The transcribed texts were repeatedly read to gain an overall understanding of the whole. The data analysis followed an inductive approach, meaning that pattern, themes or categories from the analysis were derived from the data $(91,92,98)$. The data material was the same in both parts of study I, although it was analyzed by two different methods according to the research question in each part.

\section{Qualitative content analysis}

Data from interviews in study I, Paper I, were analyzed by qualitative content analysis according to Krippendorf (91). Content analysis is considered to be useful for careful, detailed and systematic examination and interpretation. Sentences or phrases containing information relevant to the aim and the research question were identified and bundled into meaning units. The meaning units were thereafter condensed to reduce them while retaining their essence, after which they were compared for similarities and differences. Similar meaning units were given the same code. The codes were then categorized into subcategories and categories. The main investigator performed the first analysis of the transcribed text. Furthermore the research group worked individually in order not to interfere with their fellow researchers' assessment and analysis of the transcribed text. The analyses were then compared and consensus was reached. The meaning units and subcategories were subsequently reread to determine the category for each meaning unit and subcategory (91) (table 4).

Critical incident techniques

Data from interviews in study I, Paper II, were analyzed using critical incidents technique (CIT). A situation was defined as critical if it was related to the aim of the study and the interview question. A critical incident is a decisive situation if it makes a significant contribution, either positive or negative, to the general aim of the activity under investigation and if it is of great importance to the person involved (98). 
The incidents were systematically sorted in relation to content and divided into groups. Critical incidents with a similar content were labeled and grouped into subcategories that were categorized. In the final step the categories were labeled based on their comprehensive structure and main area $(92,98)$ (Table 4).

\section{Focus group interviews}

Data from the focus group interviews in study II were analyzed in accordance with Krueger (2000) until saturation was achieved (99). The transcribed interview texts formed the basis for the inductive analysis, supplemented by the assistant moderator's field notes about the group interaction $(95,100)$. All expressions that met the aim of the study were highlighted in the text. Expressions with a similar meaning were merged into subcategories that reflected the text as closely as possible. The subcategories were continuously compared to the text as a whole throughout the analysis. Subcategories with a similar meaning were then merged into categories $(95,100)$ (Table 4$)$. 
Table 4. Example of analysis processes used in study I and II.

\begin{tabular}{|c|c|c|c|c|}
\hline Study/Paper & Quotation & Subcategory & Category & Main area \\
\hline $\begin{array}{l}\text { Study I/Paper } \\
\text { I }\end{array}$ & $\begin{array}{l}\text { Information about } \\
\text { something I can } \\
\text { manage myself is } \\
\text { extremely } \\
\text { important, for example, } \\
\text { if intake of alcohol and } \\
\text { dairy products is } \\
\text { not good } \cdots \text { (no. 7) }\end{array}$ & $\begin{array}{l}\text { Behavior that } \\
\text { enhances well- } \\
\text { being }\end{array}$ & $\begin{array}{l}\text { Knowledge } \\
\text { related to } \\
\text { managing } \\
\text { everyday life }\end{array}$ & N/A \\
\hline $\begin{array}{l}\text { Study I/Paper } \\
\text { II }\end{array}$ & $\begin{array}{l}\text { "For example, if you're } \\
\text { messy down there, } \\
\text { because even if you } \\
\text { make every effort to be } \\
\text { clean, } \\
\text { it can come very quickly } \\
\text { when you're walking or } \\
\text { such, it sometimes } \\
\text { oozes out, really } \\
\text { difficult, } \\
\text { then you go ugh ...if it } \\
\text { oozes a lot when you } \\
\text { are with a girl, then it's } \\
\text { not good, as you can } \\
\text { imagine!" (no. 19) }\end{array}$ & $\begin{array}{l}\text { Leakage of } \\
\text { stool, pus and } \\
\text { blood }\end{array}$ & $\begin{array}{l}\text { Having a body } \\
\text { that smells }\end{array}$ & $\begin{array}{l}\text { The bowels rule } \\
\text { life }\end{array}$ \\
\hline $\begin{array}{l}\text { Study } \\
\text { II/Paper III }\end{array}$ & $\begin{array}{l}\text { "I think the most } \\
\text { important thing is being } \\
\text { able to come here when } \\
\text { you are in bad shape. I } \\
\text { don't think that it's } \\
\text { important to come here } \\
\text { regularly, but knowing } \\
\text { that I can come when } \\
\text { necessary." P2 (4) }\end{array}$ & Access to care & $\begin{array}{l}\text { Structure of the } \\
\text { healthcare } \\
\text { organization }\end{array}$ & N/A \\
\hline
\end{tabular}




\section{Statistical analysis}

A confirmatory factor analysis (CFA) was made to ensure construct validity of the QoC-IBD. The maximum likelihood method with varimax rotation was used for factor extraction. Only factors with an eigen value greater than 1 were extracted. Each item was affiliated to the factor on which it exerted the greatest loading. Factor loadings below 0.4 were deemed non-significant. Descriptive statistics were calculated for demographic data in study III. Test retest was measured with Spearman rank order correlation coefficient $\left(\mathrm{r}_{\mathrm{s}}\right)$ between the first and second measurement for QoC-IBD in 83 persons over a 2-week period. SPSS Statistics 22.0 was used for statistic calculation.

\section{Ethical considerations}

The studies followed the common ethical principles for clinical research regulated by the World Medical Association (WMA 2008) Declaration of Helsinki, and were approved by the Regional Ethical Review Board in Linköping, Sweden. (Dnr M209-09 and Dnr 2013/426-32). The participants were informed that participation was voluntary and that they could withdraw from participation whenever they wanted without giving an explanation. Participation was grounded on oral and written informed consent and participants were guaranteed confidentially. code lists were stored safely, and the code for each person was kept separate from the completed questionnaire in a safe place.

The critical incident techniques (I) method relies on the participants' recollection and their ability to provide a detailed account of a critical incident. It should be pointed out that there is always a possibility of causing a recall of memories that could be difficult to handle (92). In focus groups (II) there is a risk that participants may feel under pressure to agree and conform with others. To minimize this risk, the participants were informed before the interview that the aim was not to reach consensus on the perceptions of $\mathrm{HC}$, but to explore different views. Participants might also withhold information due to embarrassment $(93,95)$. All respondents were invited to contact the clinic after the interview if they needed any kind of support after participating in the studies. However, this was not necessary. 


\section{RESULTS}

\section{Characteristics of the participants}

In total, 374 persons with IBD participated in the studies included in this thesis. The participants' ages ranged from 18-88 years, mean age 49 years. The inclusion of all participants took place at a university hospital of south-east Sweden between July 2010 and September 2015. In addition to the persons with IBD, a group of $\mathrm{HC}$ professionals $(\mathrm{n}=8)$ participated in the development of the questionnaire in paper IV.

The overall aim of this thesis was to describe the knowledge need, life situation and the perception of $\mathrm{HC}$ among persons living with IBD in order to develop a questionnaire to evaluating the quality of HC. The main finding shows that there was a need for disease related knowledge, with a great individual variety (I). Trust and respect was one of the most important dimensions in the perception of HC (III). This knowledge formed the basis for the development of the questionnaire measuring quality of care, the QoC-IBD (IV).

\section{When daily life becomes affected by symptom burden}

One of the most prominent critical incidents in daily life was not being able to reach the toilet in time at work, at school, at the cinema or when travelling on public transport and being forced to get off the bus before their destination (I). The frequent loss of bowel control made it necessary to be aware of the location of toilets or forced the individual to stay at home in fear of not being able to find a toilet in time (I). The participants also described the importance of social support in difficult situations in order to manage life while living with IBD (I, II). This social support could be provided by family and next of kin, patient's associations, as well as a professional approach from $\mathrm{HC}$ professionals (I, II).

The participants described critical incidents where their bowel problems affected their possibility to live up to or realize personal goals in life. These incidents were mostly related to their professional life, such as being unable to work full-time or frequent sick leave, resulting in not being promoted and a lower salary increase. Relapse and/or symptom burden could also make them turn down job opportunities and/or promotions. Being unable to perform duties at work was another critical situation, for example, if the workplace did not have access to toilets or their duties made it difficult to rush to the toilet. Some patients had public duties, while others had assignments where they lectured to large audiences. In such situations, not being able to reach a toilet in time was critical (I). 
Some expressed feelings of making life difficult for their next of kin or being a burden to others (I). This meant that the whole family was forced to put on hold on activities or plans that had been scheduled (I). Some chose not to tell their family how sick they were because they did not want to worry them. Having strict routines helped them to manage daily life, but when they deviated from these routines, critical incidents occurred that made their situation worse. For example, they might adapt their food intake by not eating before leaving home. Strict routines and social support helped some of the patients to remain active (I).

\section{The importance of disease related knowledge}

The knowledge needs among persons with IBD focused mainly on IBD symptoms and the course of the disease. The majority wanted to become experts on their own disease by gaining knowledge about the most important parts (I). The need for knowledge was greater at the time of diagnosis, during relapses or when the persons with IBD had lived with the disease for a long time and realized that they had received insufficient information at the time of diagnosis (I).

The persons with IBD required knowledge about how to behave in everyday life to avoid worsening their condition (I). Knowledge about what to do to prevent relapse and remain in remission helped the persons with IBD to feel that they could manage everyday life to a greater extent than before. They wanted to know more about how to handle a relapse, when to contact a HC provider, and what they could do to avoid hospitalization (I).

Knowledge needs identified were being provided with information about ongoing research, challenges related to pregnancy, different treatment and examination options, hereditary factors and diet (I, II). Moreover, some perceived a lack of support about how to manage and learning to live with the illness (I, II).

The way the information from $\mathrm{HC}$ was communicated was also important. The persons living with IBD did not want to receive information when they were very ill because it was more difficult for them to assimilate the information then (I, II). They also felt that HC professionals should put more thought into how and where information is provided (I, II). Efficient communication and receiving concrete answers from the $\mathrm{HC}$ professionals were important aspects of the perception of $\mathrm{HC}$, and could also be perceived as a critical incident when it did not work (I, II). One important factor for achieving good communication was meeting with $\mathrm{HC}$ professionals in an environment that was calm and stress-free (II). 
Managing social life entailed communicating knowledge about the disease to significant others (I), as well as maintaining a dialogue and communication with $\mathrm{HC}$ professionals (II). Some felt that it was important that family, friends and colleagues had knowledge about the disease. Managing social life was also associated with being questioned and criticized by others. The support from next of kin in combination with information on how to handle symptoms and treatment enabled the persons with IBD to take care of themselves more actively (I, II). It was perceived as a challenging balance whether or not to tell others about the disease. When supervisors and colleagues knew about the disease, the support might be increased. On the other hand, the person with IBD might feel labeled as being disabled (I, II). Another way to satisfy the need for knowledge was to learn from other persons with IBD. Some expressed an appreciation of being a member of a patient association, while others felt afraid to learn from others' experiences.

The great importance of information and knowledge revealed in study I and II resulted in the inclusion of three questions about information in study III. They were (III):

10 To what extent do you experience that you have been given sufficient information?

11. To what extent do you experience that you have been given intelligible information?

12. To what extent was the information given at a suitable time point?

\section{Being met with trust and respect}

One important aspect of $\mathrm{HC}$ from the perspective of persons living with IBD was being met with respect and trust by HC professionals. This included being taken seriously, being met with an understanding of what it means to live with a disease, being shown empathy and being comforted. Trust was vital, as it enabled them not only to talk about the illness but also about their everyday life with openness and a sense of humor. When being met with a professional attitude, the persons living with IBD were enabled to better cope with a difficult situation. Consequently, this was crucial in terms of mental support (II).

Several participants wanted to meet others with the same diagnosis for group discussions, preferably with HC professionals involved. They wished to exchange experiences with others in the same situation, for example the patient's association (I, II). 
Some participants felt that as their disease is to a great extent invisible from the outside, others did not always realize how ill they were (I). They felt that authorities such as employment services, insurance companies or daycare center societies, friends and family, as well as HC professionals did not always believe them (I, II). An understanding of the difficulties talking about bowel habits and other symptoms from the gastrointestinal tract was also sometimes lacking (II). The sense of not being believed was also closely associated with not being able to meet the expectations of others (I, II), for example, feeling pressured to undergo certain examinations, or not being the perfect partner, friend or co-worker (I, II).

Trust and respect was perceived as a very important aspect of $\mathrm{HC}$ as expressed in study II. In study III, five questions were developed in this dimension (III). The five questions about trust and respect were:

1. How do you experience the healthcare professionals' ability to show an understanding of your situation?

2. How do you experience the opportunity to discuss your symptoms with the healthcare professionals?

3. How do you experience the healthcare professionals' ability to instill confidence?

4. To what extent do you experience that healthcare professionals take you seriously?

5. How do you experience the overall reception at the gastroenterology department?

\section{Being an active part of healthcare decisions}

While most of the participants in the studies expressed a wish to take part in the decision-making process and be involved in the care, some expressed a wish not to take part (I, II). One reason for not wanting to be part of the decision-making process was a feeling of being forced to take too much responsibility (II). Some perceived it difficult to understand what decisionmaking or participation meant (II). Decision-making was for some described as a form of collaboration with HC professionals (II). Having enough disease related knowledge facilitated the participants' ability to be part of the decisionmaking process and take care of themselves (I). Many participants expressed that they wanted to be met with an understanding that everyone does not fit in the same mold and that individualized care plans were required (I, II). The concept of an individualized care plan was not fully understood by everyone (II, III). A definition of a care plan was added to the questionnaire in study III after the cognitive interviews (III). 
Being involved or participating in the care seemed to have different meanings to the participants (I, II), but having sufficient disease related knowledge seemed to affect the will to be more involved in the decision-making process (I). The participants had mixed feelings about the importance of decisionmaking. It was therefore decided to keep the importance questions about decision-making. Five questions were developed in study III concerning decision-making.

6. To what extent do you experience that you take part in your own care?

7. How important is it for you to take part in decisions about your own care?

8. Do you have an individual care plan* for your continued care and treatment?

8.1. If 'yes' how aware are you of the care plan content?

9. To what extent do you experience that the care is adapted to your individual needs?

*Care plan: By care plan, we refer to a written plan describing the measures/actions/follow-up that is planned based on your need for care/treatment/appointments.

Continuity of care was considered, as it creates a sense of security during periods of relapse. Encountering the same HC professionals was perceived as the most important aspect when having a complicated disease (II). As well as for decision-making the participants had divided opinions about the importance of continuity of care. Therefore the importance questions about continuity of care were kept. Questions developed in study III concerning continuity were:

13. To what extent do you experience that you have an opportunity to meet or contact the same healthcare professionals?

14. How important is it for you to have an opportunity to contact the same healthcare professionals? 


\section{I mportant aspects of quality of care}

As described above, the results from study I and II generated the dimensions for perceptions of $\mathrm{HC}$ that were used in the question generation in study III, subsequently forming the basis for the QoC-IBD. The most important aspects were, trust and respect, decision-making, information, continuity of care, access to care and satisfaction with $\mathrm{HC}$ as a whole (Figure 2). The first version of the questionnaire had 24 questions on importance and 24 questions on performance. After two evaluation phases, the final questionnaire consisted of 21 questions in the same dimensions, but the importance questions were kept only for decision-making and continuity of care (Figure 2).

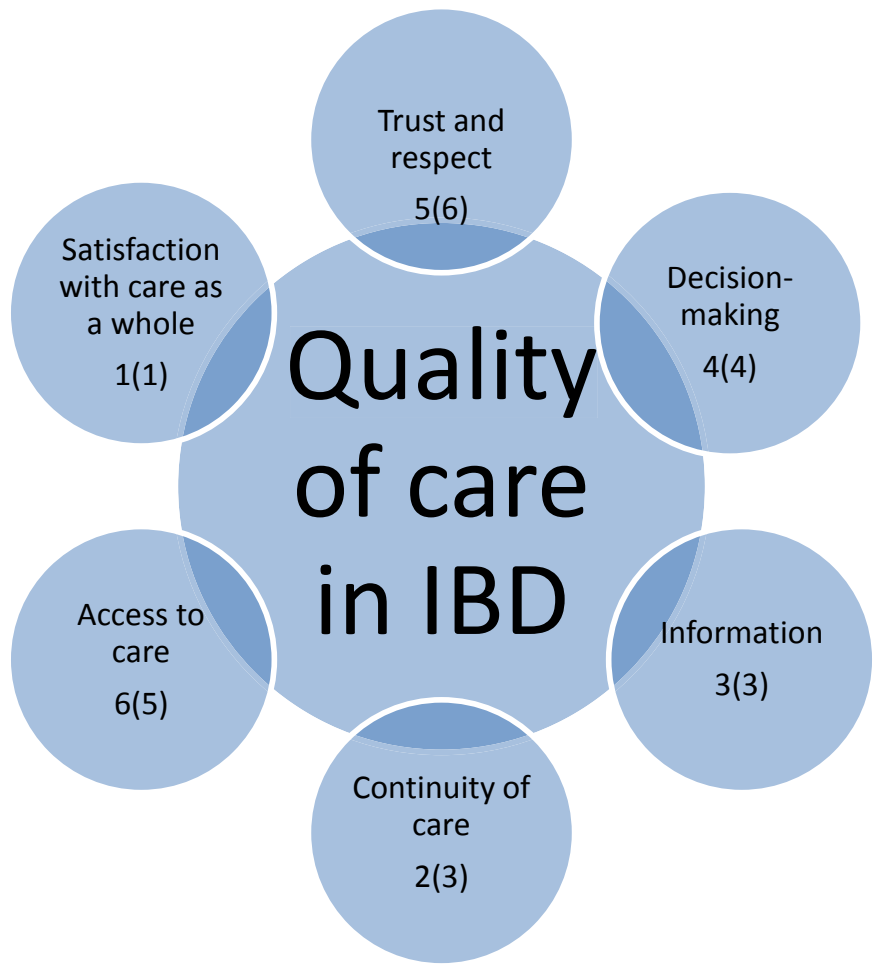

Figure 2

Dimensions important for quality care from the perspective of persons living with IBD.

Number of questions in the final version of the QoC-IBD questionnaire in each dimension. Number of questions in the first version of the questionnaire in brackets. 
Cognitive interviews were used in the evaluation phase of the questionnaire. In this phase some difficulties to understand concepts emerged and a few questions were reformulated (III). For instance, the question "I receive assistance quicly when needed", was changed to number 15.4 below. One question was developed (III) concerning access to care with six subquestions.

15. In the past year, did you experience that:

15.1 You did not receive your prescriptions on time?

15.2 The clinic canceled a scheduled appointment?

15.3 You had to wait long in the waiting room?

15.4 You were not seen when your condition acutely worsened?

15.5 You could not get through on the phone during telephone hours?

15.6 You did not receive a doctor's note in time?

The final question in the QoC-IBD was about satisfaction with $\mathrm{HC}$ as a whole, with response options, which ranged on a scale from 1 to 10 .

16) How satisfied are you with the care as a whole?

Satisfied

12

$2 \quad 3$

3
$4 \quad 5$

6
Not satisfied

$9 \quad 10$

The last part in study III was the measurement evaluation in phase III. In this phase, four factors were identified in the factor analysis (III). In total, the four factors explained $61 \%$ of the variance. The question about participation was loading both in factor two and four and was placed in factor two, which had the greatest loading. One single question about receiving prescriptions on time loaded in factor four, and was therefore forced into factor three. The three final factors evolving in the analyses were trust and respect, decision-making and access to care. 
Test-retest correlation measured with Spearman for the QoC-IBD ranged between $\mathrm{r}_{\mathrm{s}}$ 0.36-0.68 (Md $\left.\mathrm{r}_{\mathrm{s}} \mathrm{O} .60\right)$ at a significant level at 0.01. The questions showing lowest correlation were;

8. Do you have an individual care plan for your continued care and treatment? $\left(\mathrm{r}_{\mathrm{s}} \mathrm{0.36}\right)$.

15.2. The clinic canceled a scheduled appointment? ( $\mathrm{r}_{\mathrm{s}} 0.43$ )

4. To what extent do you experience that healthcare professionals take you seriously? $\left(\mathrm{r}_{\mathrm{s}} 0.52\right)$.

The three questions showing highest correlation were;

3. How do you experience the healthcare professionals' ability to instill confidence? ( $\mathrm{r}_{\mathrm{s}} \mathrm{0.68}$ ).

13. To what extent do you experience that you have the opportunity to meet or contact the same healthcare professionals? $\left(\mathrm{r}_{\mathrm{s}} \mathrm{0.68}\right)$.

16. How satisfied are you with the care as a whole? $\left(\mathrm{r}_{\mathrm{s}} 0.67\right)$.

Internal consistency reliability for QoC-IBD was $\alpha=0.811$. The internal consistency for QUOTE-IBD was $\alpha=0.908$.

The question non-response of the QoC-IBD ranged between 0.7- 3.9\%. The question with the highest non-response rate was about individual care need (Q.9). In the QUOTE-IBD, the question non-response ranged between 1.0 6.5\% for the importance questions and 27.6\%-40.5\% for the performance questions. The performance questions with the highest non-response rates were "should allow the patients to have input in decisions regarding treatment received"(Q.4), and "In case of acute problems a doctor should be available within 24 hours” (Q.10). 


\section{DISCUSSION}

Some important steps in the area of quality of care and IBD have been taken both in Sweden and worldwide. The result of this thesis is a small step towards improving the quality of IBD care. The overall aim of this thesis was to describe the knowledge need, life situation and the perception of $\mathrm{HC}$ among persons living with IBD in order to develop a questionnaire to evaluate the quality of HC. The results give new insights into the life situation of persons with IBD as well as into what quality of care means to them.

\section{When daily life become affected by symptom burden}

Losing control of one's bowel has a great impact on daily life for persons living with IBD (I). In the western society, social norms and taboos limit the ability to talk about bowel habits and symptoms from the gastrointestinal tract (I). Even telling family members about symptoms could be difficult (I). One finding in study I was that persons with IBD felt unable to meet both their own expectations and those of others, which had a great impact on their daily life. Societal norms for how a parent, sibling, partner, and colleague should act contributed greatly to these expectations, and the symptom burden made it sometimes difficult to live up to the expectations (I, II). A meta-analytic review of psychosocial adjustment showed that adolescent and children with IBD demonstrate poorer social functioning than healthy children, but that they are similar comparable to children with other chronic illnesses (101). In addition, in study I in this thesis, it was shown that social and personal expectations can create a feeling of insecurity as well as a sense of not being good enough (I). Not being believed or seen could also be due to a lack of social support (I). In a study by Sewitch (2001), it was shown that in comparison with healthy controls, persons with IBD received support from a significantly smaller number of people, but higher levels of satisfaction with social support. Patients with an active disease were generally less satisfied with their social support than those who were in remission (102). By listening to the patient's story and support initiatives to social relations the patient's social support may increase what in turn may improve psychological distress and health.

\section{The importance of disease related knowledge}

The need for knowledge among persons with IBD as well as the importance and need for $\mathrm{HC}$ professionals to share information is a central part in $\mathrm{HC}$ encounters (I, II). Most of the participants in this thesis wanted to know more about their disease and the course of the disease (I). Disease related knowledge was a way for the participants to take active care of themselves. Disease related knowledge meant a sense of control over the disease (I, II). 
By gaining knowledge, the persons with IBD could participate to a greater extent in the decision-making process (I). The literature supports that the patient should be viewed as an equal partner who participates in their care to an extent of their own choice (103). To achieve an optimal partnership, the patient needs to be involved in their care at an early stage (104). The results in this thesis support the assumption that it is important that patients are given the knowledge they need to manage their disease (I, II). Knowledge needs were individual and changed over time, (I, II) which indicates that HC professionals need to adapt the information and education to the individual. There are some previous studies about, for example, IBD schools $(74,105)$. Evaluations of these showed that patients appreciate education as part of their care (73). Consequently, patient education should be introduced at different stages of the course of the disease (106). The result in study I shows that most of the knowledge transmission seems to best provided individually. However some participants expressed a need for interacting with other persons living with IBD, and this can be achieved in "IBD schools", or through patients associations.

The need for knowledge was the greatest at the time of diagnosis and during relapse (I, II). Although many different factors probably combined to explain the reasons for wanting or not wanting knowledge, some had no interest in receiving information (avoidance behavior), while others searched for knowledge. Miller (1987) labeled these two types of personalities 'blunter' and 'monitor' (107). 'Monitors' are people who seek information that can help them cope with stress, while 'blunters' avoid any new information when faced with a stressful situation (107). Patients with IBD need some basic knowledge to manage the disease (I), alleviate their worries and improve their adherence (108) . Lack of knowledge of IBD complications can have disastrous consequences leading, for example, to an underestimation of the importance of colorectal cancer surveillance (109).

Recent research has confirmed that information on many aspects of their disease remains insufficient among persons with IBD. Furthermore, information needs can differ in various patient groups, according to gender, age and type of disease (110). Appropriate information and a better understanding of the individual's needs and concerns should be considered potential components for improving patient-related outcomes, such as adherence to advice and treatment, quality of life, or stress (111).

Using open questions and paying attention to feedback from persons with IBD may help to identify knowledge needs. 
In a structured care plan, knowledge needs are addressed by ensuring that the information is individualized and concretized, and consists of what is important to the individual, including guidance on how to cope with situations when living with IBD.

\section{Being met with trust and respect}

In this thesis, respect and mutual trust were described as being listened to, being taken seriously, being met with empathy, and being seen as an individual in the social context of working life, family life and leisure time. Mutual trust and being treated with respect are often taken for granted, but the results reveal that persons with IBD do not always experience it as such (II). Studies have shown that the meaning of disrespect encompasses long waiting times, receiving incomplete information about their condition, or $\mathrm{HC}$ professionals not being truthful in the event of a medical error $(52,112)$. This thesis confirms the literature by showing that persons with IBD feel that they are not always confirmed and treated with respect (52). This has important consequences for $\mathrm{HC}$ as $\mathrm{HC}$ professionals need to find out what respect means to the individual person. According to Kantian theories, it is important to preserve individual rights and freedom, and human beings ought to be treated with respect (113).

The findings in study II show the importance of establishing a respectful and trusting relationship, thus facilitating persons with IBD and HC professionals working as a team in order to meet individual care needs (II).

A large survey by Quigley (2013) included five items (explains things; listens carefully; gives easy to understand instructions; shows respect; and spends enough time) assessing patients' perception of physicians' communication with patients. The study showed that the most important communication predictor of patients' overall physician rating is showing respect (114).

From a social psychological perspective, respect has been described as the social acceptance of another person (115). The humanistic clinical psychologist Carl Rogers advocated approaching patients by respecting them as individuals with an incontestable worth as they are, without expecting or demanding of them to behave differently to earn respect (116). Through carefully listening to the patients' experience and story is one way to be respectful, mutual respect also is of importance in the encounter between the patient and $\mathrm{HC}$ professionals.

Being respectful also means that HC professionals cannot impose their own values on patients and demand changes because they consider themselves to be the experts. Patients' behavior may, on the surface, not always seem rational. 
For example, why else would so many patients refrain from taking their prescribed medicine? The benefits of treating patients respectfully are likely to be substantial.

Respect creates trust, and having a trusting relationship makes it far more likely that the patient and $\mathrm{HC}$ professionals can work together as partners. A partnership facilitates a care plan that patients are more likely to agree to and willing to follow (117).

\section{Being an active part of healthcare decisions}

In this thesis, being involved in the care or part of the decision-making process seemed to be of great importance from several perspectives (I, II). In line with the literature (103), the results in this thesis show that by providing the right conditions for communication and mutual cooperation, a partnership can be created (II). The literature supports this finding and informal elements, such as emotionally supportive relationships, are important for ultimately determining the level of shared decision-making, paving the way for patients participations in care decisions $(104,117)$.

Having knowledge about the disease was an important factor that seemed to be associated with wanting to be a part of the decision-making process (I). However, some clearly expressed that they felt pressured by HC professionals to be actively involved in the care even though they did not want to (I, II). The fact that not all patients want to be involved in shared decision-making is supported in the literature and there are various reasons, including a lack of education, or lack of interest in learning about the details of their options (118). It is the HC professionals' responsibility to identify how active a role the patients want to have, and then provide the best person centered care possible (103). Shared decision-making may be defined as the process of interaction with patients who wish to be involved in making decisions. The concept of shared decision-making entails that $\mathrm{HC}$ professionals have the responsibility to inform and recommend treatment to patients, but the process of deciding on how to act is shared (117). The goal is to enhance patient involvement and, on the basis of the available evidence, facilitate 'evidence-based patient choice'. The increased attention to shared decision-making derives from a number of different factors. These factors include a move from the idea of informed consent to 'informed choice', the patient's legal rights and the changing nature of medical practice (119).

In the final version of the QoC-IBD, the importance questions were excluded, except for decision-making and continuity of care. 
The reason to keep the questions on the importance of decision-making was due to the fact that this concept was perceived as multi-faceted by the persons with IBD during the development of the QoC-IBD. Baars et al. (118) demonstrated that persons with IBD have a desire to be actively involved in the decision-making process; $81 \%$ reported it to be 'very important' to be actively involved in the decision-making process, and another $17 \%$ rated it as 'quite important'. When asked how their treatment could be improved, 50\% wanted close, equitable collaboration with their physician. This preference was significantly associated with disease duration of $\geq 8$ years. Gender and type of IBD were not significantly associated with patients' preferences (118). Younger age and higher socioeconomic class has been shown to predict a higher interest in involvement in shared decision-making, but no association with other sociodemographic variables, illness characteristics or beliefs about medications have been demonstrated (120). This is consistent with the results in this thesis, where elderly women in particular preferred not to be part of the decision-making process. Shared decision-making and self-management support aim to improve the quality of care (121), and are therefore an important aspect of quality of care.

\section{Important aspects of quality of care}

The purpose of measuring quality is to create a basis for improving. The QoCIBD was developed as a part of this thesis, aiming to measure quality of care among persons living with IBD. Persons with IBD took part in both the development and evaluation phase in study III. Including persons with IBD in the development of a questionnaire is regarded as a relatively new but important approach $(85,122)$. The dimension of quality of care measured in study III were; trust and respect, decision-making, information, continuity of care, access to care and satisfaction with $\mathrm{HC}$ as a whole (Figure 1). The results from study II show that these dimensions were the most prominent aspects of quality of care as did the interviews from the development phases in study III. The dimension questions were generated from these interviews (III) and the final questionnaire consisted of 21 questions. "Quality of care" refers to the worth or excellence of various attributes of medical care. Most definitions focus on the care encounter or episode and include attributes such as the technical process of care (for example, diagnosis and management) and interpersonal features of the provider-patient relationship (78). The assessment of quality of care in this thesis mainly focused on the interpersonal features of the provider-patient relationship.

The focus group and cognitive interviews in study III showed that the respondents found it unnecessary to ask for importance aspects that are obviously of great importance. 
It is important not to pose extra burden on the patients by asking questions that are not relevant (123). For this reason, it was decided to exclude the questions about importance in the final version of the QoC-IBD, except for the two questions on decision- making and continuity of care.

Lifelong follow-up with continuous contacts with the IBD team are crucial to maintain remission (124).Thus, an adequate quality of care plays an important role for persons with IBD (76), and the need for a valid and reliable questionnaire to assess quality of care in IBD is well founded. Measuring quality of care among people receiving care is a prerequisite for improving quality of care.

\section{Methodological discussion}

\section{Validity and reliability}

This thesis is based on three studies using both qualitative and quantitative data in order to describe knowledge need, the life situation and the perception of $\mathrm{HC}$ among persons living with IBD.

In qualitative research, openness and methodological transparence with regard to data collection are considered important (125). Systematic data collection through individual interviews (I), focus group interviews (II) and a systematic analysis was applied throughout the studies. Four criteria to establish trustworthiness of the qualitative findings were applied; credibility, dependability, confirmability, and transferability (126).

The participants were selected in order to obtain a variety of aspects regarding need for knowledge, critical incidents, and perception of $\mathrm{HC}$, which strengthens the credibility of the results (I). Another strength is the large number of participants $(\mathrm{n}=30)(\mathrm{I}),(\mathrm{n}=26)(\mathrm{II})$, as the sample size in qualitative studies is usually considerably smaller. All interviews were conducted by the main investigator and it was ensured that the participants focused on the same issues to guarantee credibility, as subtle changes in the wording of a question can lead to significant changes in the response (I, II). Credibility was also established by presenting relevant quotations from the transcribed text to further illustrate the categories (I, II). Dependability was increased by conducting two pilot interviews to ensure that the questions were relevant and properly formulated. Dependability was also ensured by the fact that the interviews were conducted and audio-taped by the same person (I, II). All authors selected meaning units from the first three interviews, while in the following 10 interviews, the first and last authors selected meaning units individually and compared them (I). 
Seeking consensus among the co-researchers throughout the analysis process also contributed to the confirmability of the results (I, II). Confirmability implies that the researcher should remain objective (125). The main investigator who conducted the interviews is an IBD nurse. To prevent bias due to pre-understanding, all authors independently read and analyzed the text from the interviews until consensus was reached (127). The detailed description of the participants, data collection, and analysis and study context permits the reader to assess the transferability of the results (I, II).

An accurate account of the data collection and analysis, as well as a description of the participants strengthened the dependability and transferability of the studies (I, II). It is always possible to refer to the raw data, even though it is up to the reader to evaluate the transferability of the results. As the studies were carefully designed, conducted and analyzed, the results may be transferable to other people with IBD living in similar context (I, II) $(126,128)$.

In quantitative research validity and reliability are considered to be of great importance. Content validity was assured by relying on the knowledge of an expert group familiar with IBD and questionnaire development (III). The experts were provided with access to the questionnaire and were asked to provide feedback on how well each question measured the construct in question. Content validity was also assured by a focus group interview with three patients and individual interviews with ten patients about the relevance of the questions (III). Their feedback was then analyzed and informed decisions were made about the effectiveness of each question.

A CFA was performed to assure construct validity (III). The CFA resulted in four factors. However, in factor four, one single question was loading and therefore it was forced into three factors. The three factors in the analyses were; trust and respect, decision-making and access to care. The items about information and continuity of care ended up in the factor decision-making. This might be logical as information and communication could be viewed as a part of the concept decision-making. Continuity of care also ended up in the same factor, and continuity of care might be important for the perception of being an active part of the care. Concepts regarding quality of care blend into each other, which becomes noticeable in a factor analysis. Separating quality of care into dimensions might create a structure of the questions in the questionnaire, although it might not serve any other purpose as the dimensions are not used to calculate quality impact. 
Test-retest with Spearman rank order correlation coefficient for the QoC-IBD ranged between $\mathrm{r}_{\mathrm{s}} 0.36-0.68\left(\mathrm{Md} \mathrm{r}_{\mathrm{s}} 0.60\right), \mathrm{p} \leq 0.01$. It is desirable with a level at $r_{s}>0.7$, which means that the result shows an unsatisfactory reliability for some questions. The reasons may be that it was asked for their experience of care in the past 12 month. It can be difficult for the patient to have a clear idea because they may have met several healthcare contacts during the past year. Even in the cognitive interviews the patients raised the difficulties to answer questions about the perception of care thinking back a whole year. In a revised version, it might be more suitable to evaluate a specific care situation. The internal consistency reliability was Cronbach's alphaa $=0.811$. This shows that there is concordance in the outcome of the various parts of the questionnaire. Cronbach's a for the importance questions in the QUOTE-IBD was $\alpha=0.908$. This is quite high, and therefore it may be assumed that the questions are similar too each other, which is a limitation (125).

Drop out and question non response study IV

The response rate in study IV was $49 \%$, which is reasonable, as response rates to questionnaires are declining in many countries $(94,129)$. This is particularly noticeable among the young (130). We could have sent two reminders instead of one, but ethical approval was only given for one. The validation process should not have been affected by the low response rate as the aim was not to describe the population or to generalize the results.

Questions non-response rate in the QoC-IBD was low, ranging between o, 7- 3, $9 \%$, showing good acceptability with the highest non-response in the question about individual care need. It might be difficult to understand what is meant by an individual care need and this question might need to be reworded due to the number of non-responders. The high response rate in the QoC-IBD indicates good acceptability. In the QOUTE-IBD, all questions on Importance had a response rate above $90 \%$, whereas the response rate for some questions in "Performance" was as low as $60 \%$. This was also seen in the Portuguese validation study of the QOUTE- IBD, where $69 \%$ of the patients answered all questions on Performance (89) and $64 \%$ of the patients answered all questions on Importance and Performance. This is similar to the Portuguese validation study were only $59 \%$ of the patients completed all the questions (89). Study III indicates that there are problems with the QOUTE-IBD in terms of acceptability, due to the low response rate in the performance questions. In our study, as well as in other studies, the reason for the high question nonresponse rate in the QUOTE-IBD may be that several questions are specific to the interaction with a special group of professionals or a specific HC situation, such as questions regarding the competence of nurses at the endoscopy unit, physicians' communication with other HC professionals, or whether prescribed 
medications are included in the drug benefit program. It is hard to answer a question if a specific event has not been experienced in the past 12 months. The low response rate in the performance questions also complicates the calculation of the quality impact of the QUOTE-IBD. 


\section{Conclusions}

In conclusion, persons with IBD want knowledge about their disease and its treatments. Disease related knowledge seems to be of the greatest need when first diagnosed, during relapse or when have lived with the disease for a long time without receiving sufficient information at the time of diagnosis.

Disease related knowledge is important in order to understand and accept their state of illness and to be able to develop a care plan together with HC professionals. The care plan should guide the patients to deal with the disease so that daily life is affected as little as possible.

The uncertain nature of IBD creates critical incidents that causes individuals to avoid social interaction, place considerable demands on the family situation, and that may affect their professional life. The results demonstrate the importance of establishing a respectful and trusting relationship, facilitating persons with IBD and HC professionals to work as a team in order to meet individual care needs. The encounter between the person with IBD and HC professionals forms the basis for a partnership were persons with IBD are involved in decisions that optimize and match their personal care preferences. This knowledge led to the development of the QoC-IBD, which is a short, selfadministered questionnaire with promising validity and reliability, measuring the subjective experience of quality of care in persons with IBD. It was designed in close collaboration with persons with IBD to really capture their perception of quality of care. The QoC-IBD seems to be easy to use, and it can enable clinicians and researchers to identify targets for improvement.

\section{Clinical implication}

As all patients have different care needs, it is important to adapt care to each individual patient, for example, by working in a person-centered way. A person-centered approach can also reduce adverse incidents as the patient becomes the watchdog of their own care, taking precautionary measures against flaws in a pressured HC system. HC professionals' ability to actively involve and reflect on the care situation together with the person living with IBD is essential in order to develop individual care plans and implement shared decision-making. 


\section{Future research}

This thesis has provided new ideas for future research involving persons with IBD and quality of care:

- Revision and further validity testing of the questionnaire QoC-IBD.

- Language translation and cultural adaption of the QoC-IBD, in order to make international comparisons of quality of care.

- By using the QoC-IBD to identify areas of improvement, and evaluate systematic changes in IBD care to develop the IBD care. 


\section{POPULÄRVETENSKAPLIG SAMMANFATTNING}

Inflammatorisk tarmsjukdom (IBD) är en sjukdomsgrupp som omfattar sjukdomarna Crohn's sjukdom och ulcerös kolit. De vanligaste symtomen är diarré, blodtillblandad avföring, buksmärtor, trötthet och viktnedgång. Sjukdomarna är kroniska och går oftast i skov. Vanligast är att man insjuknar tidigt i livet, mellan 15-35 års ålder. I Sverige lever ungefär 61 ooo personer med IBD med en jämn fördelning mellan könen. Orsaken till att man făr IBD är okänd, men en kombination av flera faktorer bland annat genetik och miljö, tycks samverka.

Eftersom IBD är kroniska sjukdomar är kontakten med hälso- och sjukvården livslång. Personer med kroniska sjukdomar behöver kunskap om sjukdomen för att kunna hantera sina symtom och ta en aktiv roll i sin vård.

Det övergripande syftet med denna avhandling var att beskriva livssituationen såväl som uppfattningen av hälso- och sjukvården bland personer som lever med IBD för att förbättra hälso- och sjukvårdens kvalitet.

De tre studier, och fyra vetenskapliga artiklar som ingår i avhandlingen genfördes på en magtarmmedicinsk klinik i sydöstra Sverige mellan åren 2010 till 2015. Totalt deltog 374 personer med IBD i åldrarna 18 till 88 år och 8 personer från olika yrkeskategorier.

I den första studien intervjuades 30 personer. Syftet var att beskriva kunskapsbehovet och kritiska situationer i relation till sjukdom och det dagliga livet. Kunskapsbehovet som personerna beskrev var relaterat till sjukdomsförlopp, hur man hanterar det dagliga livet och svårigheter att förstå och ta till sig kunskap. Det fanns stora variationer i hur behovet av kunskap såg ut, störst behov fanns när personerna var nyinsjuknade och/eller hade ett skov av sjukdomen. Många av de kritiska händelserna handlade om rädsla att förlora kontrollen över tarmen, att inte kunna leva upp till sina egna och andras förväntningar, frustration över behandlingar som inte fungerade och biverkningar av behandlingar.

Den andra studien syftade till att undersöka upplevelser kring vården. Fokusgrupps intervjuer, och två individuella intervjuer, genomfördes med sammanlagt 26 personer med IBD. Två huvudkategorier framkom där den ena handlade om hälso-och sjukvårdspersonalens attityder och den andra om hur 
vården är organiserad. Den viktigaste delen i hälso- och sjukvårdpersonalens attityder var betydelsen att bli bemött med respekt och ömsesidigt förtroende. Inom kategorin kring organisation var tillgängligheten till vård den viktigaste faktorn för en god vård.

I den tredje studien utvecklades ett frågeformulär för att mäta vårdkvalitet utifrån resultatet från studie I och II i avhandlingen. Frågeformuläret bestod av 21 frågor om upplevelser kring vården det senaste året. Frågorna var inom områdena respekt och bemötande, delaktighet, information, kontinuitet, tillgänglighet till vård och övergripande nöjdhet med vården. Sist i formuläret fanns även möjlighet att skriva fritext om sina upplever om det är något man saknade i formuläret.

Sammanfattningsvis är sjukdomsrelaterad kunskap viktig för att förstå och acceptera sin sjukdom. Den sjukdomsrelaterade kunskapen är nödvändig för att kunna ta en aktiv roll i sin vård. Resultaten visar vikten av att upprätta ett respektfullt och tillitsfullt förhållande och att möta individuella vårdbehov i ett partnerskap mellan personen med IBD och hälso- och sjukvårdspersonal. Denna kunskap ledde till utvecklingen av QoC-IBD, som är ett frågeformulär, som mäter den subjektiva erfarenheten av vårdkvalitet hos personer med IBD. Det är utformat i nära samarbete med personer med IBD för att verkligen fånga deras uppfattning om vårdkvalitet.

Ett sätt att använda resultatet av avhandlingen i den kliniska verksamheten är att arbeta på ett sätt som stärker förtroendet för vården och dela ansvaret med personen som lever med sjukdomen. 


\section{REFERENCES}

1. Casati J, Toner BB, de Rooy EC, et al. Concerns of patients with inflammatory bowel disease: a review of emerging themes. Digestive diseases and sciences. 2000;45:26-31

2. Ricci C, Lanzarotto F, Lanzini A. The multidisciplinary team for management of inflammatory bowel diseases. Digestive and liver disease : official journal of the Italian Society of Gastroenterology and the Italian Association for the Study of the Liver. 2008;40 Suppl 2:S285-288

3. Calvet X, Panes J, Alfaro N, et al. Delphi consensus statement: Quality Indicators for Inflammatory Bowel Disease Comprehensive Care Units. Journal of Crohn's \& colitis. 2014;8:240-251

4. Danese S. New therapies for inflammatory bowel disease: from the bench to the bedside. Gut. 2012;61:918-932

5. Pihl-Lesnovska K, Hjortswang H, Ek AC, et al. Patients' perspective of factors influencing quality of life while living with Crohn disease. Gastroenterology nursing : the official journal of the Society of Gastroenterology Nurses and Associates. 2010;33:37-44; quiz 45-36

6. Cosnes J, Gower-Rousseau C, Seksik P, et al. Epidemiology and natural history of inflammatory bowel diseases. Gastroenterology. 2011;140:1785-1794

7. Xavier RJ, Podolsky DK. Unravelling the pathogenesis of inflammatory bowel disease. Nature. 2007;448:427-434

8. Baillie M. The morbid anatomy of some of the most important parts of the human body. London: J. Johnson and G. Nicol; 1793

9. Kirsner JB. Historical origins of current IBD concepts. World journal of gastroenterology : WJG. 2001;7:175-184

10. Aufses AH, Jr. The history of Crohn's disease. The Surgical clinics of North America. 2001;81:1-11, vii

11. Riddell RH. Pathology of idiopathic inflammatory bowel disease. . In: Balfour SArtor R, Sandborn WJ, eds. Kirsner's Inflammatory Bowel Disease. Sixth Edition ed. Philadelphia, USA: WB Saunders; 2004:399-425

12. Khor B, Gardet A, Xavier RJ. Genetics and pathogenesis of inflammatory bowel disease. Nature. 2011;474:307-317

13. Viennois E, Zhao Y, Merlin D. Biomarkers of Inflammatory Bowel Disease: From Classical Laboratory Tools to Personalized Medicine. Inflammatory bowel diseases. 2015;21:2467-2474

14. Fakhoury M, Negrulj R, Mooranian A, et al. Inflammatory bowel disease: clinical aspects and treatments. Journal of inflammation research. 2014;7:113-120

15. Jess T, Riis L, Vind I, et al. Changes in clinical characteristics, course, and prognosis of inflammatory bowel disease during the last 5 decades: a population-based study from Copenhagen, Denmark. Inflammatory bowel diseases. 2007;13:481-489 16. Henriksen M, Jahnsen J, Lygren I, et al. Clinical course in Crohn's disease: results of a five-year population-based follow-up study (the IBSEN study). Scandinavian journal of gastroenterology. 2007;42:602-610

17. Wolters FL, Russel MG, Sijbrandij J, et al. Phenotype at diagnosis predicts recurrence rates in Crohn's disease. Gut. 2006;55:1124-1130 
18. Lakatos PL. Prediction of disease course in inflammatory bowel diseases. World journal of gastroenterology : WJG. 2010;16:2589-2590

19. Liu JZ, van Sommeren S, Huang $\mathrm{H}$, et al. Association analyses identify 38 susceptibility loci for inflammatory bowel disease and highlight shared genetic risk across populations. Nat Genet. 2015;47:979-986

20. Ananthakrishnan AN. Epidemiology and risk factors for IBD. Nature reviews Gastroenterology \& hepatology. 2015;12:205-217

21. Ananthakrishnan AN. Environmental risk factors for inflammatory bowel diseases: a review. Digestive diseases and sciences. 2015;60:290-298

22. Molodecky NA, Soon IS, Rabi DM, et al. Increasing incidence and prevalence of the inflammatory bowel diseases with time, based on systematic review. Gastroenterology. 2012;142:46-54 e42; quiz e30

23. Burisch J, Pedersen N, Cukovic-Cavka S, et al. East-West gradient in the incidence of inflammatory bowel disease in Europe: the ECCO-EpiCom inception cohort. Gut. 2014;63:588-597

24. Veloso FT. Extraintestinal manifestations of inflammatory bowel disease: do they influence treatment and outcome? World journal of gastroenterology : WJG. 2011;17:2702-2707

25. Lee YM, Kaplan MM. Primary sclerosing cholangitis. The New England journal of medicine. 1995;332:924-933

26. Hartman C, Eliakim R, Shamir R. Nutritional status and nutritional therapy in inflammatory bowel diseases. World journal of gastroenterology : WJG. 2009;15:2570-2578

27. Olsen KO, Juul S, Bulow S, et al. Female fecundity before and after operation for familial adenomatous polyposis. The British journal of surgery. 2003;90:227-231

28. Johnson P, Richard C, Ravid A, et al. Female infertility after ileal pouch-anal anastomosis for ulcerative colitis. Diseases of the colon and rectum. 2004;47:11191126

29. Moller FT, Andersen V, Wohlfahrt J, et al. Familial Risk of Inflammatory Bowel Disease: A Population-Based Cohort Study 1977-2011. The American journal of gastroenterology. 2015;110:564-571

30. Truelove SC, Witts LJ. Cortisone in ulcerative colitis; final report on a therapeutic trial. Br Med J. 1955;2:1041-1048

31. Edwards FC, Truelove SC. The Course and Prognosis of Ulcerative Colitis. Gut. 1963;4:299-315

32. Langholz E, Munkholm P, Davidsen M, et al. Colorectal cancer risk and mortality in patients with ulcerative colitis. Gastroenterology. 1992;103:1444-1451

33. Truelove SC. Evolution of olsalazine. Scandinavian journal of gastroenterology Supplement. 1988;148:3-6

34. Travis SP, Stange EF, Lemann M, et al. European evidence-based Consensus on the management of ulcerative colitis: Current management. Journal of Crohn's \& colitis. 2008;2:24-62

35. Travis SP, Stange EF, Lemann M, et al. European evidence based consensus on the diagnosis and management of Crohn's disease: current management. Gut. 2006;55 Suppl 1:i16-35 
36. Sjoberg $\mathrm{M}$, Magnuson A, Bjork J, et al. Infliximab as rescue therapy in hospitalised patients with steroid-refractory acute ulcerative colitis: a long-term follow-up of 211 Swedish patients. Alimentary pharmacology \& therapeutics. 2013;38:377-387

37. Gomez-Gomez GJ, Masedo A, Yela C, et al. Current stage in inflammatory bowel disease: What is next? World journal of gastroenterology : WJG. 2015;21:1128211303

38. Nielsen OH. New Strategies for Treatment of Inflammatory Bowel Disease. Frontiers in Medicine. 2014;1

39. Bernstein CN, Walker JR, Graff LA. On studying the connection between stress and IBD. The American journal of gastroenterology. 2006;101:782-785

40. Mawdsley JE, Rampton DS. Psychological stress in IBD: new insights into pathogenic and therapeutic implications. Gut. 2005;54:1481-1491

41. Mawdsley JE, Rampton DS. The role of psychological stress in inflammatory bowel disease. Neuroimmunomodulation. 2006;13:327-336

42. Goodhand JR, Wahed M, Mawdsley JE, et al. Mood disorders in inflammatory bowel disease: relation to diagnosis, disease activity, perceived stress, and other factors. Inflammatory bowel diseases. 2012;18:2301-2309

43. van Langenberg DR, Gibson PR. Factors associated with physical and cognitive fatigue in patients with Crohn's disease: a cross-sectional and longitudinal study. Inflammatory bowel diseases. 2014;20:115-125

44. Zhang M, Hong L, Zhang T, et al. Illness perceptions and stress: mediators between disease severity and psychological well-being and quality of life among patients with Crohn's disease. Patient preference and adherence. 2016;10:2387-2396

45. Knowles SR, Cook SI, Tribbick D. Relationship between health status, illness perceptions, coping strategies and psychological morbidity: a preliminary study with IBD stoma patients. Journal of Crohn's \& colitis. 2013;7:e471-478

46. Knowles SR, Gass C, Macrae F. Illness perceptions in IBD influence psychological status, sexual health and satisfaction, body image and relational functioning: A preliminary exploration using Structural Equation Modeling. Journal of Crohn's \& colitis. 2013;7:e344-350

47. Gibson PR, Vaizey C, Black CM, et al. Relationship between disease severity and quality of life and assessment of health care utilization and cost for ulcerative colitis in Australia: a cross-sectional, observational study. Journal of Crohn's \& colitis. 2014;8:598-606

48. Stjernman H, Tysk C, Almer S, et al. Worries and concerns in a large unselected cohort of patients with Crohn's disease. Scandinavian journal of gastroenterology. 2010;45:696-706

49. Jaghult S, Saboonchi F, Johansson UB, et al. Identifying predictors of low healthrelated quality of life among patients with inflammatory bowel disease: comparison between Crohn's disease and ulcerative colitis with disease duration. Journal of clinical nursing. 2011;20:1578-1587

50. Hall NJ, Rubin GP, Dougall A, et al. The fight for 'health-related normality': a qualitative study of the experiences of individuals living with established inflammatory bowel disease (ibd). Journal of health psychology. 2005;10:443-455 
51. Lonnfors S, Vermeire S, Greco M, et al. IBD and health-related quality of life -discovering the true impact. Journal of Crohn's \& colitis. 2014;8:1281-1286

52. Kairos F. IBD2020 Survey. Verlag and Supria; 2013

53. Sykes DN, Fletcher PC, Schneider MA. Balancing my disease: women's perspectives of living with inflammatory bowel disease. Journal of clinical nursing. 2015;24:2133-2142

54. Almadani SB, Adler J, Browning J, et al. Effects of inflammatory bowel disease on students' adjustment to college. Clinical gastroenterology and hepatology : the official clinical practice journal of the American Gastroenterological Association. 2014;12:2055-2062 e2051

55. Busch K, da Silva SA, Holton M, et al. Sick leave and disability pension in inflammatory bowel disease: a systematic review. Journal of Crohn's \& colitis. 2014;8:1362-1377

56. Hoivik ML, Moum B, Solberg IC, et al. Work disability in inflammatory bowel disease patients 10 years after disease onset: results from the IBSEN Study. Gut. 2013;62:368-375

57. Barlow C, Cooke D, Mulligan K, et al. A critical review of self-management and educational interventions in inflammatory bowel disease. Gastroenterology nursing : the official journal of the Society of Gastroenterology Nurses and Associates. 2010;33:11-18

58. Gochman D S. Health behavoir Research: Definitions and Diversity. In the D S Gochman handbook of health behavior research. New York: Plenum Press; 1997

59. Clark NM, Zimmerman BJ. A Social Cognitive View of Self-Regulated Learning About Health. Health Education \& Behavior. 2014;41:485-491

60. Davis TC, Williams MV, Marin E, et al. Health literacy and cancer communication. CA: a cancer journal for clinicians. 2002;52:134-149

61. Arora NK. Interacting with cancer patients: the significance of physicians' communication behavior. Soc Sci Med. 2003;57:791-806

62. Simon CM, Kodish ED. Step into my zapatos, doc: understanding and reducing communication disparities in the multicultural informed consent setting. Perspectives in biology and medicine. 2005;48:S123-138

63. Teutsch C. Patient-doctor communication. The Medical clinics of North America. 2003;87:1115-1145

64. Jones SC, Gallacher B, Lobo AJ, et al. A patient knowledge questionnaire in inflammatory bowel disease. J Clin Gastroenterol. 1993;17:21-24

65. Leong RW, Lawrance IC, Ching JY, et al. Knowledge, quality of life, and use of complementary and alternative medicine and therapies in inflammatory bowel disease: a comparison of Chinese and Caucasian patients. Digestive diseases and sciences. 2004;49:1672-1676

66. O'Sullivan M, O'Morain C. Patient knowledge in inflammatory bowel disease. The American journal of gastroenterology. 2000;95:2128-2129

67. Robinson A, Thompson DG, Wilkin D, et al. Guided self-management and patient-directed follow-up of ulcerative colitis: a randomised trial. Lancet. 2001;358:976-981

68. Fallowfield L, Saul J, Gilligan B. Teaching senior nurses how to teach communication skills in oncology. Cancer nursing. 2001;24:185-191 
69. Liebowitz J. Knowledge Management Handbook: Adelphi: CRC Pr I Lic; 1999

70. Irvine EJ. Review article: patients' fears and unmet needs in inflammatory bowel disease. Alimentary pharmacology \& therapeutics. 2004;20 Suppl 4:54-59

71. Moser G, Tillinger W, Sachs G, et al. Disease-related worries and concerns: a study on out-patients with inflammatory bowel disease. European journal of gastroenterology \& hepatology. 1995;7:853-858

72. Schwarz SP, Blanchard EB. Evaluation of a psychological treatment for inflammatory bowel disease. Behaviour research and therapy. 1991;29:167-177

73. Larsson K, Sundberg Hjelm M, Karlbom U, et al. A group-based patient education programme for high-anxiety patients with Crohn disease or ulcerative colitis. Scandinavian journal of gastroenterology. 2003;38:763-769

74. Oxelmark L, Magnusson A, Lofberg R, et al. Group-based intervention program in inflammatory bowel disease patients: effects on quality of life. Inflammatory bowel diseases. 2007;13:182-190

75. Scholmerich J, Sedlak P, Hoppe-Seyler P, et al. The information needs and fears of patients with inflammatory bowel disease. Hepatogastroenterology. 1987;34:182185

76. Elkjaer M, Moser G, Reinisch W, et al. IBD patients need in health quality of care ECCO consensus. Journal of Crohn's \& colitis. 2008;2:181-188

77. Kennedy AP, Rogers AE. Improving patient involvement in chronic disease management: the views of patients, GPs and specialists on a guidebook for ulcerative colitis. Patient education and counseling. 2002;47:257-263

78. Donabedian A. Methods for deriving criteria for assessing the quality of medical care. Medical care review. 1980;37:653-698

79. Lohr KN. Medicare: a strategy for quality assurance. Journal of quality assurance : a publication of the National Association of Quality Assurance Professionals. 1991;13:10-13

80. Organization WH. Quality of Care: A process for making strategic choices in health systems. In: (WHO) WHO, ed. Genéve; 2006

81. Socialstyrelsen. Nationella indikatorer för god vård. In: Socialstyrelsen, ed. Stockholm; 2009

82. Wilde B, Starrin B, Larsson G, et al. Quality of care from a patient perspective--a grounded theory study. Scandinavian journal of caring sciences. 1993;7:113-120

83. Melmed GY, Siegel CA. Quality improvement in inflammatory bowel disease. Gastroenterology \& hepatology. 2013;9:286-292

84. Donabedian A, Eisenberg J, Gellhorn A, et al. The quest for quality health care: whose choice? Whose responsibility? The Mount Sinai journal of medicine, New York. 1989;56:406-422

85. van der Eijk I, Sixma H, Smeets T, et al. Quality of health care in inflammatory bowel disease: development of a reliable questionnaire (QUOTE-IBD) and first results. The American journal of gastroenterology. 2001;96:3329-3336

86. Pallis AG, Kostagiolas PA, Mouzas IA, et al. Patients' perceptions as an indicator of quality of care, in Greek patients with inflammatory bowel disease. Scandinavian journal of caring sciences. 2009;23:93-99 
87. Melmed GY, Siegel CA, Spiegel BM, et al. Quality indicators for inflammatory bowel disease: development of process and outcome measures. Inflammatory bowel diseases. 2013;19:662-668

88. Masachs M, Casellas F, Borruel N, et al. Validation of the Spanish version of a questionnaire to measure quality of care through the eyes of patients with inflammatory bowel disease (QUOTE-IBD). Inflammatory bowel diseases. 2010;16:982-992

89. Soares JB, Nogueira MC, Fernandes D, et al. Validation of the Portuguese version of a questionnaire to measure Quality of Care Through the Eyes of Patients with Inflammatory Bowel Disease (QUOTE-IBD). European journal of gastroenterology \& hepatology. 2015;27:1409-1417

90. O'Connor M, Bager P, Duncan J, et al. N-ECCO Consensus statements on the European nursing roles in caring for patients with Crohn's disease or ulcerative colitis. Journal of Crohn's \& colitis. 2013;7:744-764

91. Krippendorf. Content analysis: an introduction to its methodology. California: SAGE Publications inc; 2004

92. Norman IJ, Redfern SJ, Tomalin DA, et al. Developing Flanagan's critical incident technique to elicit indicators of high and low quality nursing care from patients and their nurses. Journal of advanced nursing. 1992;17:590-600

93. Krueger RA, Casey MA. Focus Group: A practical Guide for Applied Research. 5:th ed. United States of America: SAGE Publications, Inc; 2015

94. Tolonen H, Helakorpi S, Talala K, et al. 25-year trends and socio-demographic differences in response rates: Finnish adult health behaviour survey. European journal of epidemiology. 2006;21:409-415

95. Krueger RA. Analyzing \& Reporting Focus Group Results. Thousands Oaks, California: SAGE Publications Ltd.; 1998

96. Polit DF, Beck CT. Nursing Research: Generating and Assessing Evidence for

Nursing Practice. Ninth edition ed; 2012

97. Collins D. Cognitive interviewing practice. London: SAGE Publications Ltd; 2014

98. Flanagan JC. The critical incident technique. Psychological bulletin. 1954;51:327358

99. Krueger RA, Casey MA. Focus groups; a practical guide for applied research. Thousands Oaks, CA: SAGE Publisher Ltd; 2000

100. Krueger RA. Analyzing focus group interviews. Journal of wound, ostomy, and continence nursing : official publication of The Wound, Ostomy and Continence Nurses Society / WOCN. 2006;33:478-481

101. Greenley RN, Hommel KA, Nebel J, et al. A meta-analytic review of the psychosocial adjustment of youth with inflammatory bowel disease. Journal of pediatric psychology. 2010;35:857-869

102. Sewitch MJ, Abrahamowicz M, Bitton A, et al. Psychological distress, social support, and disease activity in patients with inflammatory bowel disease. The American journal of gastroenterology. 2001;96:1470-1479

103. Thórarinsdóttir K, Kristjánsson K. Patients' perspectives on person-centred participation in healthcare. Nursing Ethics. 2013;21:129-147

104. Cribb A, Entwistle VA. Shared decision making: trade-offs between narrower and broader conceptions. Health Expectations. 2011;14:210-219 
105. Jaghult S, Larson J, Wredling R, et al. A multiprofessional education programme for patients with inflammatory bowel disease: a randomized controlled trial. Scandinavian journal of gastroenterology. 2007;42:1452-1459

106. Ekman I. Personcentrering inom hälso- och sjukvården. Egypten: Liber AB; 2014

107. Miller SM. Monitoring and blunting: validation of a questionnaire to assess styles of information seeking under threat. Journal of personality and social psychology. 1987;52:345-353

108. Cooper JM, Collier J, James V, et al. Beliefs about personal control and selfmanagement in 30-40 year olds living with Inflammatory Bowel Disease: a qualitative study. International journal of nursing studies. 2010;47:1500-1509

109. Subasinghe D, Wijekoon NS, Nawarathne NM, et al. Disease-related knowledge in inflammatory bowel disease: experience of a tertiary care centre in a developing country in South Asia. Singapore Med J. 2010;51:484-489

110. Pittet V, Vaucher C, Maillard MH, et al. Information Needs and Concerns of Patients with Inflammatory Bowel Disease: What Can We Learn from Participants in a Bilingual Clinical Cohort? PLoS One. 2016;11:e0150620

111. Bissonnette JM. Adherence: a concept analysis. Journal of advanced nursing. 2008;63:634-643

112. Ekman I, Swedberg K, Taft C, et al. Person-centered care--ready for prime time. European journal of cardiovascular nursing : journal of the Working Group on Cardiovascular Nursing of the European Society of Cardiology. 2011;10:248-251

113. Kant I. The critique of practical reason New York: Liberal Arts Press; 1956

114. Quigley DD, Martino SC, Brown JA, et al. Evaluating the content of the communication items in the CAHPS((R)) clinician and group survey and supplemental items with what high-performing physicians say they do. Patient. 2013;6:169-177

115. Gaines Jr SO. Relationships between members of cultural minorities. Understudied relationships: Off the beaten track. Thousand Oaks, CA, US: Sage Publications, Inc; 1995:51-88

116. Patterson $\mathrm{CH}$. Respect (Unconditional Positive Regard). The Therapeutic Relationship. Monterey, CA: Brooks/Cole; 1985:59-63

117. Wolf A, Moore L, Lydahl D, et al. The realities of partnership in person-centred care: a qualitative interview study with patients and professionals. BMJ open. 2017;7

118. Baars JE, Markus T, Kuipers EJ, et al. Patients' preferences regarding shared decision-making in the treatment of inflammatory bowel disease: results from a patient-empowerment study. Digestion. 2010;81:113-119

119. Charles C, Gafni A, Whelan T. Shared decision-making in the medical encounter: what does it mean? (or it takes at least two to tango). Soc Sci Med. 1997;44:681-692

120. Garfield S, Smith F, Francis SA, et al. Can patients' preferences for involvement in decision-making regarding the use of medicines be predicted? Patient education and counseling. 2007;66:361-367

121. Dixon-Woods M, McNicol S, Martin G. Ten challenges in improving quality in healthcare: lessons from the Health Foundation's programme evaluations and relevant literature. BMJ Qual Saf. 2012;21:876-884 
122. Larsson G, Larsson BW, Munck IM. Refinement of the questionnaire 'quality of care from the patient's perspective' using structural equation modelling. Scandinavian journal of caring sciences. 1998;12:111-118

123. Hagell P, Westergren A. The significance of importance: an evaluation of Ferrans and Powers' Quality of Life Index. Quality of life research : an international journal of quality of life aspects of treatment, care and rehabilitation. 2006;15:867-876 124. Loftus EV, Jr., Schoenfeld P, Sandborn WJ. The epidemiology and natural history of Crohn's disease in population-based patient cohorts from North America: a systematic review. Alimentary pharmacology \& therapeutics. 2002;16:51-60

125. Polit DF, Beck CT. Nursing Research: generating and assessing evidence for nursing practice. Eighth Edition ed. New York: Lippincott Williams \& Wilkins; 2004 126. Lincoln Y, Guba E. Naturalistic inquiry. CA: Sage Publications; 1985 127. Fridlund B, Hildingh C. Qualitative Research Methods in the Service of health. Lund: Studentlitteratur; 2000

128. Polit DF, Beck CT. Nursing Research: Principles and Methods: Lippincott Williams \& Wilkins; 2004

129. Curtin R, Presser S, Singer E. Changes in telephone survey nonresponse over the past quarter century. Public opinion quarterly. 2005;69:87-98

130. Ekholm O, Hesse U, Davidsen M, et al. The study design and characteristics of the Danish national health interview surveys. Scandinavian journal of public health. 2009;37:758-765 


\section{Papers}

The papers associated with this thesis have been removed for copyright reasons. For more details about these see:

http:// urn.kb.se/ resolve?urn=urn:nbn:se:liu:diva-142720 